\title{
The Norm of Wage Negotiations in the United States*
}

\author{
Melisa Demirović \\ University of Cologne \\ Blaine G. Robbins \\ New York University Abu Dhabi
}

March 2 ${ }^{\text {nd }}, 2022$

Word Count: 11,743 (abstract, text, references)

Key words: wage negotiations, social norms, moral economy, factorial survey experiment

Corresponding author: Blaine G. Robbins, Division of Social Science, New York University Abu Dhabi, Building A5 1191, PO Box 129188, Abu Dhabi, United Arab Emirates.

Email: bgr3@nyu.edu

* The Division of Social Science at New York University Abu Dhabi generously funded this research. 


\begin{abstract}
The moral economy is a set of institutionalized rules, norms, and values that guide action in market economies. Historically, the norm of wage negotiations has been a central pilar of the U.S. moral economy, but extant research suggests that this may be changing. In the present study, we seek to evaluate whether the norm of wage negotiations is decoupled from the U.S. moral economy. To do so, we map the character of the norm of wage negotiations, and identify the extent to which the norm is strong or weak along four dimensions: polarity, conditionality, intensity, and consensus. Results of a factorial survey experiment administered to a quota sample of U.S. adults $(N=707)$ indicate that the norm of wage negotiations is weak: it is largely bipolar, conditional, and of a low-to-moderate intensity, with disagreement over the norm as well as the circumstances demarcating the norm. These deep social cleavages, however, do not fall along demographic lines: the character of the norm is comparable across demographic groups. Overall, our findings support the idea that there has been an erosion of the distributional norms underlying the U.S. moral economy.
\end{abstract}




\section{Introduction}

In standard economic models of wage bargaining, wage agreements are a function of three key inputs: preferences, self-interest, and bargaining power (Nash 1950; Rubinstein 1982; Schelling 1960). While these models are powerful tools for explaining the complexities and nuances of wage bargaining, they have been criticized for giving too little attention to nonpecuniary factors in a worker's decision on whether or not to negotiate for a higher salary (Elster 1989ab). Building from Elster’s (1989ab) seminal work, there has been growing interest in understanding whether societal factors, like social norms, shape wage negotiations (Exley et al. 2020; Katzenstein 1985; Swenson 1989; Western and Rosenfeld 2011).

This turn toward social norms is particularly relevant given how labor markets are deeply entrenched in — and difficult to separate from—a wider moral economy (Arnold 2001; Booth 1994; Fourcade and Healy 2007; Mau 2003). The moral economy is a set of institutionalized rules, norms, and values that guide individual actions and attitudes in market economies (Polanyi 1944; Scott 1976; Thompson 1971). For any given population, the moral economy can be understood as “a popular consensus about legitimate and illegitimate practices of social exchange (Sachweh 2012:422).” In modern market economies, these legitimate practices rest on shared notions of justice and fairness (Mau 2003), and for wage bargaining in particular, the fair distribution of wages and equality in pay serve as pillars of the modern moral economy (Western and Rosenfeld 2011). But as Western and Rosenfeld (2011) suggest, these pillars may be slowly crumbling away.

This research implies that a set of institutionalized rules and norms—or moral economy — may guide wage negotiations in the U.S. labor market. But whether a norm of wage bargaining exists in the United States remains underexamined, and begs the question: Is there a 
social norm of wage negotiations in the United States? If so, what is the "character" (Jasso and Opp 1997) of this social norm? Does the norm encourage wage negotiations? Does it hold under all circumstances? Do individuals intensely subscribe to the norm? And does the American public widely share the norm?

To answer these questions, we design a factorial survey experiment (FSE) of wage negotiations (Auspurg and Hinz 2015). As leading scholars of social norms argue, FSEs are particularly well-suited to measuring the four aspects of a social norm that denote its "character" (Horne et al. 2018; Jasso and Opp 1997; Jasso 2006; Robbins et al. 2022; Rossi and Berk 1985): (1) polarity, whether a norm for a given individual is prescriptive (permit and endorse behavior), proscriptive (prohibit and oppose behavior), bipolar (both prescriptive and proscriptive), or nonexistent (an individual does not subscribe to the norm); (2) conditionality, whether a norm for a given individual holds under all or some circumstances; (3) intensity, the degree to which an individual subscribes to a norm; and (4) consensus, the extent to which members of a population share a norm.

With this design, we provide a comprehensive evaluation of the U.S. public’s approval of wage negotiations, how conditional that approval is on the characteristics of those who may or may not negotiate, and how much consensus there is within and between demographic groups. Most importantly, the proposed FSE eliminates problems of internal validity inherent in observational studies via random assignment. Negotiation conditions and preferences that are correlated in real life, such as occupation and earnings, are orthogonal by design in our experiment. We can, in other words, test and directly compare the independent effects of conditions that demarcate the norm of wage negotiations. And because we use a sample of the 
general population, we can make population-level claims about the norm of wage negotiations more broadly.

Our findings show that the majority of Americans embrace a norm of wage negotiations. The norm, however, is weak, with disagreement over the norm as well as the circumstances demarcating the norm. But these deep social cleavages do not fall along demographic lines. The norm—and the conditions serving as boundaries of —are comparable across demographic groups. Our results support the idea that the norm of wage negotiations is decoupled from the U.S. moral economy.

\section{Social Norms and the Norm of Wage Negotiations: Theoretical and Empirical Background} Four Aspects of a Social Norm

A social norm is a rule about a particular behavior, with some degree of consensus, that is socially enforced (Coleman 1990; Horne and Mollborn 2020). Norms—and rules in particularare statements claiming that "persons ought or ought not to act in a certain way (Gibbs 1965:589, italics in original; see also Opp 2013).” When there is a social norm, individuals who do or do not follow the rules, invite rewards and punishments, respectively, from those who subscribe to the norm (Coleman 1990; Hechter and Opp 2001; Horne 2009). As Williams (1968) classically wrote: "Norms are rules for behaving: they say more or less specifically what should or should not be done by particular types of actors in given circumstances (p. 284).” These definitions highlight four key aspects of a social norm (Grigoryeva and Robbins 2021; Horne et al. 2018; Jackson 1966; Jasso and Opp 1997; Rauhut and Winter 2010; Robbins et al. 2022; Rossi and Berk 1985). First, norms might vary in their polarity: they can be prescriptive, proscriptive, bipolar, and/or nonexistent. Second, norms might vary in their conditionality: they can hold under all (unconditional) or some (conditional) circumstances. Third, norms might vary in their 
intensity: individuals can differ in the degree to which they subscribe to a norm (e.g., low, moderate, or high). Fourth, norms might vary in their level of consensus: they can be shared by all or only a few members of society.

Polarity. Mapping the character of a norm begins by identifying its polarity for each individual. Polarity means that for any given individual, a person can uniformly oppose a focal action or behavior regardless of the circumstances (proscriptive), uniformly endorse a behavior regardless of the circumstances (prescriptive), oppose and endorse a behavior depending on the circumstances (bipolar), or neither oppose nor endorse a behavior since there may not be a norm or rule guiding the focal action (nonexistent). Establishing a norm's polarity is fundamentally important for institutional analysis. If each individual in a population, for instance, prescribes a behavior, e.g., recycling, then we would expect behavior to follow said prescriptions.

Conditionality. One should also evaluate whether the norm under study is unconditional: "under all circumstance should an individual perform X" or "under no circumstances should an individual do $X$ ”. If a social norm is conditional, scholars must probe the circumstances in which the norm applies. Most norms are conditional. Even some universal norms, such as the norm of reciprocity, has limits placed on the circumstances in which it does or does not hold. Returning a favor in some cultures may not be appropriate if the target of reciprocation is an out-group member. Conditionality, then, is the degree to which a social norm—-for any given individual— holds under all circumstances, where circumstances refer to characteristics of the situation and/or the situations' interactants. Unlike polarity, conditionality identifies the degree to which an individual varies in their evaluation of a norm in light of shifting circumstances. For instance, individual A might uniformly proscribe wage negotiation, but nonetheless vary the magnitude of their proscriptions depending on the circumstances. Individual B, by contrast, might uniformly 
proscribe wage negotiations to the same degree regardless of the circumstances. Individual A in this example subscribes to a conditional norm, while individual B subscribes to an unconditional norm. For any given person, an unconditional norm may be prescriptive or proscriptive, but never bipolar; a conditional norm, by contrast, may be prescriptive, proscriptive, or bipolar. A bipolar norm, by definition, is always a conditional norm.

Intensity. Intensity is the degree to which an individual subscribes to a norm. For instance, individuals A and B might both uniformly proscribe wage negotiations, but the degree of this proscription could be "not at all strong” for individual A and "extremely strong” for individual B. While individual A and individual B both feel obligated to conform to the norm to negotiate, the magnitude of each individual's personal obligations and expectations varies.

Consensus. Consensus refers to the degree to which individuals in the population share a norm. It can "be described as the homogeneity of acceptance [emphasis added] concerning the validity of one particular norm within a population (Rauhut and Winter 2010: 1183).” Consensus is demonstrated by identifying the extent to which a norm is shared within and between subpopulations, and ultimately rests on the amount of between-individual variation in a norm (Jasso 2006). Consensus is important for understanding the shared character of a norm in a population. Some norms vary within subpopulations but not between, while other norms vary to a great extent within and between subpopulations. Gaining knowledge of how a norm is shared in a population specifies how strong or weak a norm might be. For instance, if half of the individuals in a population uniformly proscribe wage negotiations while the other half uniformly prescribe wage negotiations, this would suggest disagreement (or a lack of consensus) in the norm to negotiate. Given disagreement in the population, the next step is to identify which traits 
or characteristics are common among subpopulations (e.g., men might be more likely to prescribe wage negotiations than women).

Our goal, then, is to ascertain: (1) the norm of wage negotiations to which people in the U.S. population subscribe, if any; (2) the character of each individual respondent's normpolarity, conditionality, and intensity; and (3) the homogeneity of acceptance (or interrespondent consensus).

\section{The Norm of Wage Negotiations}

Modern market economies are embedded in a moral economy, or a set of collectively shared institutionalized rules, norms, and values (Arnold 2001; Booth 1994; Fourcade and Healy 2007; Mau 2003). These norms and values guide the structure of social and economic exchange, including the exchange of land, food, and labor (Polanyi 1944). With respect to the latter, the moral economy — and social norms in particular-appear to play an important part in wage negotiations.

Consider one of the early statements on the topic: Jon Elster's (1989ab) model of wage bargaining and social norms. Elster contends that "norms of equality, equity, and fair division shape the outcome of bargaining generally and of collective wage bargaining in particular (Elser 1989b: 113).” For Elster, two norms stand out, namely the norm of equality and the norm of equity. In the course of bargaining, the norm of equality may be invoked, which claims equal pay for everyone, regardless of occupation or type of work. A person's output—salary, hourly wage, etc.- - is independent of one's inputs. Other norms may also be invoked during the bargaining process, such as the norm of equity: to each proportionality to his or her $\delta$, where $\delta$ includes effort, hardship, skill, education, seniority, or contribution to output. Elster argues that these norms can come in various forms, such as strong or weak versions. They can also conflict, serve 
as obstacles to wage agreements, and lead to bargaining impasse. On the other hand, norms of equality and equity can help workers and firms overcome problems created by a "plurality of cooperative arrangements (Elster 1989b: 113).”

Empirical research strongly suggests that norms are important determinants of wage negotiations in the moral economy. Western and Rosenfeld (2011) argue that labor unions foster norms of equity, and contribute to "a moral economy that [institutionalizes] norms for fair pay, even for nonunion workers (p. 514).” For Western and Rosenfeld (2011), unions solidify distributional norms that protect low-wage workers and combat the "injustice of unchecked earnings for managers and owners (p. 518).” Yet, from 1973 onwards, private sector union membership in the United States has declined dramatically, marking an "erosion of the moral economy and its underlying distributional norms (Western and Rosenfeld 2011:514).” Western and Rosenfeld's (2011) analysis of union membership shows that declines in organized labor contributed to the dramatic growth of inequality in the United States.

Other norms besides equality and equity, however, may undergird the moral economy of wage negotiations. Some scholars suggest that wage negotiations are a specific instance of claims-making (Tilly 1999; Tomaskovic-Devey and Avent-Holt 2019), such that one’s “claimsmaking power emanates from relationships among positions and status groups, rather than individual skills or proclivities (Sauer et al. 2021: 935).” As Sauer et al. (2021) write: "subordinate-status actors will often avoid making claims they believe others will see as outside the norm for a person of their status in that interactional context (p. 939, emphasis added).” Norms surrounding positions and status are important for who can and cannot negotiate for higher wages. In this regard, multiple status distinctions are important, such as gender, race, and occupational status. Sauer et al. (2021) find that subordinate-status actors, when in a job that 
permits negotiation, are less likely to exercise that option: women, people in lower-class jobs, and people with temporary contracts are less likely to negotiate even when given the opportunity. While norms go unobserved in Sauer et al. (2021), Exley et al. (2020) show that they do exist for female workers, but yield unintended consequences for women. In two lab experiments, Exley et al. (2020) show that the counterfactual condition of always negotiating does not benefit women, and that forcing women to negotiate serves "as a caution against the recommendation that women should negotiate more (p. 845).” This finding implies that if traditional "lean-in” advice is normative in the United States, it disproportionately imposes costs on women. To explore how widespread the sentiment is that "women should negotiate more," the authors conducted two additional experiments. In these experiments, Exley et al. (2020) implemented a "third party" design, where a third person exogenous to the worker-firm dyad can influence a worker's ability to opt out of negotiations. By eliciting an incentivized measure of norms (Krupka and Weber 2013), Exley et al. (2020) find that there is a societal norm favoring increased negotiations for women over those for men.

Thus, there appear to be norms governing entry into wage negotiations in the moral economy. But these norms are not unconditional, claiming that any person, regardless of their position or status, should negotiate under all circumstances. As for polarity, although the emphasis in previous research has been on proscriptive norms and prescriptive norms, the norm of wage negotiations likely includes all three types: prescriptive, proscriptive, and bipolar. Thus, studying polarity in the norm of wage negotiations is an important research endeavor. Finally, the level of intensity and consensus are obviously central concerns in the study of wage negotiations.

\section{Data and Methods}


To measure the norm of wage negotiations in the United States, we employed a FSE design (Auspurg and Hinz 2015; Jasso 2006). FSEs present respondents with hypothetical scenarios (vignettes) that reflect real-life situations and stimuli. Within each scenario or vignette, researchers manipulate attributes of the situation (dimensions) by randomly assigning attribute values (levels) to elicit judgments, decisions, or intentions with one or more dependent variables (evaluation task). In this study, we presented a quota sample of U.S. adults with ten vignettes describing fictive workers, Person A and Person B. We used a number of norm-relevant dimensions, such as Person A’s and B’s gender and race, to characterize their circumstances. Each dimension consisted of two or more manipulated levels (e.g., Black and White) that we randomly assigned to respondents. We then asked respondents to evaluate and judge whether Person A in each vignette should or should not negotiate for a higher salary.

\section{The Respondent Sample}

An online survey and FSE were administered to a sample of respondents drawn from Qualtrics’ online survey platform. Qualtrics fielded the study in January and February 2020 to a quota sample that was proportionally representative of the college-educated, employed U.S. population by age cohort, gender, and education. Qualtrics contacted 1,371 web panel participants. 707 participants completed the study, yielding a 51.6 percent completion rate. In terms of relative majorities, 50.92 percent of the respondents were male, 34.79 percent had a bachelor’s degree or greater, 77.51 percent were non-Hispanic White, and 32.39 percent were between the ages of 18 and $34(M=46.35, S D=16.54, \min =18, \max =85)$. As can be seen, Qualtrics produces samples that are reflective of the U.S. population, where previous assessments find that Qualtrics' samples average within 7 percent of corresponding values in the U.S. population along key demographic variables (Heen et al. 2014). 
The Qualtrics study consisted of 4 blocks, the order of which was fixed from respondentto-respondent: Block 1 (consent form), Block 2 (screener question), Block 3 (demographic characteristics), and Block 4 (vignettes). Participants who completed the survey received an incentive based on the length of the survey, their specific panelist profile, and respondent acquisition difficulty. The specific type of compensation varied (e.g., cash, airline miles, etc.). Eligibility was restricted to U.S. adults age 18 and older who (a) voluntarily consented to participate, (b) met quota requirements based on age, gender, and education, and (c) passed a screener question at the beginning of the survey. ${ }^{1}$ Those who failed (a), (b), or (c) were prohibited from participating in the study. The median survey length was approximately 10.60 minutes.

\section{Demographic Characteristics}

One goal of our study is to investigate whether the norm of wage negotiations is universal or specific to subpopulations based on age, race, gender, and SES. We measured age as a continuous variable. We measured and restricted gender to males and females. We restricted our race-ethnicity variable to non-Hispanic Whites and Non-Whites. To measure SES, we used two variables: education and income. Highest educational attainment was categorized as high school diploma or lower, some college, and Bachelor's degree or higher. The "high school diploma or lower” category consisted of respondents who had (a) no high school diploma, and (b) received a high school diploma, GED, or high school equivalence certification. The "some college" category consisted of respondents who received an Associate’s degree or completed some

\footnotetext{
${ }^{1}$ To bolster data quality, we used a screener question at the start of the survey (Berinsky et al. 2014). Respondents who read the question's instructions were told to select the "Other" category to a question about one's favorite meal of the day, and type "Instructions processed". Those respondents who selected this specific, atypical response were eligible to participate in the study.
} 
college courses but did not receive a degree. The "Bachelor’s degree or higher” category consisted of individuals who had graduated with a Bachelor's, Master's, Professional, or Doctorate degree. To measure household income, we took the midpoints of closed income categories. We then adjusted for household size (divided midpoint values by total household size) and natural log the adjusted values. This produced a logged per capita household income adjusted for household size.

Control variables. To account for possible confounding at the individual-level, we controlled for various demographic characteristics, including marital status, employment status, cohabitation status, and region. We omitted estimates of the control variables from all tables to conserve space since our focus is on testing whether the norm of wage negotiations varies by age, race, gender, and SES.

Summary statistics and descriptions of all individual-level variables used in the present study are in the Appendix (Table A1).

\section{The Vignette Samples}

Vignette dimensions and levels. The first step in constructing our FSE was to select circumstances relevant to setting the norm's boundaries. The vignette characteristics we used to capture "potentially normatively relevant information (Jasso and Opp 1997:951)" were based on three separate sources of information.

First, the willingness of a person to negotiate for a higher wage is frequently based on the reference point against which offers and concessions are judged (Lewicki et al. 2006). The typical wage negotiation anchors on several different reference points, including the worker's current wage and the least amount the worker is willing to accept. But in most jobs, workers generally do not know their market value, and consequently anchor on, and compare their 
income to, the wages of coworkers (Clark and Oswald 1996). For instance, Card et al. (2012) randomly selected a subset of University of California employees to receive an email informing them of their pay. Employees who discovered that their pay was below the median income were less satisfied with their salary and more interested in leaving than above-median-income earners. Given this key reference point, our design consists of a dyadic social comparison whereby respondents judge whether Person A—in comparison to Person B—should negotiate for a higher salary. While realistic, this design feature limits the generalizability of our results. The norm of wage negotiations may exhibit a different character for reference points centered on market value. We discuss this issue in greater detail in the discussion and conclusion.

Second, we were also informed by recent fairness of earnings research (Auspurg et al. 2017; see also Jasso and Rossi 1977; Jasso and Webster 1997). In Auspurg et al. (2017), the authors manipulated up to 12 characteristics of a fictive person, such as age, gender, degree, occupation, and earnings among others, and asked respondents to assess the fairness of this hypothetical person's monthly gross earnings. We borrow certain design features of Auspurg et al. (2017) and apply them to our social comparison experiment. Third, and most importantly, we were guided by the previously reviewed literature on the norm of wage negotiations in the United States.

Given the literature, thirteen vignette dimensions were manipulated (see Table 1), consisting of status group and earnings characteristics of Person A and Person B. ${ }^{2}$ To avoid

\footnotetext{
${ }^{2}$ Like most FSEs, we chose to manipulate a finite number of characteristics of Person A and Person B. While this strategy undermines cognitive overload and fatigue effects-which can increase measurement error and non-response bias-it also decreases the generalizability and scope of our findings (Auspurg and Jäckle 2017; Robbins and Kiser 2018). In other words, estimates of a social norm and elements of a research design are tightly coupled (Jasso 2006). Estimates of consensus and conditionality, for instance, may vary as a function of job performance and the health status of workers, both of which we omit from our research design. While these characteristics are important to explore in future research, the goal of our
} 
number-of-level effects (see Auspurg and Hinz 2015, p. 20), we restricted the number of levels manipulated per dimension to no more than three. And following convention (Wallander 2009), our manipulated levels included high and low values or the presence and absence of vignette characteristics. $^{3}$

Informed by relational inequality theory (Sauer et al. 2021; Tilly 1999; TomaskovicDevey and Avent-Holt 201), we manipulated a number of status groups that encompass multiple categorical distinctions (see also Auspurg et al. 2017). The most common distinctions being gender, race, age, education, level of experience, and occupation. For gender, we distinguished between male and female for Person A and Person B. We restricted race to Black and White for Person A and Person B. While other ethnoracial groups can be manipulated, we focused on Blacks and Whites since they exhibit the largest racial pay gap in the United States (McCall 2001). With respect to age, we manipulated 30 years old and 50 years old for Person A and Person B. Our motivation behind selecting these two age categories is that the relative majority of the American workforce is between the ages of 30 and 50, with a median age of roughly 42 (Bureau of Labor Statistics 2020).

For education, we restricted our manipulations to workers with a high school diploma and those with a college degree, roughly constituting the two most common educational attainment categories in the United States. Following Auspurg et al. (2017), we manipulated level of experience with "little experience” and "a lot of experience.” Although qualitative labels like “little” or “a lot” are vague, lending to greater measurement error in responses (Schaeffer

study is to see whether people approve of (or support) wage negotiations under commonplace bargaining conditions. Our study, then, is a conservative test of the norm of wage negotiations in the United States. ${ }^{3}$ Methodological research finds that 13 vignette dimensions may produce inconsistent evaluations via learning and order effects, especially when respondents are shown more than 10 vignettes and evaluate complex rating tasks (Auspurg and Jäckle 2017). We guard against these issues by randomly assigning 10 vignettes to respondents and using relatively simple evaluation tasks (i.e., bipolar scales). 
1991), quantitative values would have produced implausible combinations (e.g., a 30-year-old white man with a high school diploma having 20 years of labor market experience). Simply dropping implausible combinations would have undermined the orthogonality of our experimental design. Regarding occupation, we included a single dimension that characterized the occupation of Person A and Person B, creating a situation where both persons are colleagues in the same workplace. The levels of occupation consisted of unskilled (cashier) and semi-skilled (social worker) workers. Skilled occupations such as medical doctors, lawyers, clinical psychologists and the like were not used in the design due to implausible combinations (e.g., a medical doctor with a high school degree). ${ }^{4}$

Beyond differences in status groups, we also manipulate the earnings of Person A and Person B to explore whether (a) the magnitude of monthly gross earnings, and (b) the inequality of earnings between Person A and Person B serve as conditions for the norm of wage negotiations. Our position is that earnings act as a normative boundary: individuals will believe that others should (should not) negotiate for a higher salary when their monthly gross earnings are unfairly low (high). Observers concerned with fairness norms will react more strongly to Person A’s low (high) earnings, and prescribe (proscribe) wage negotiations (Elster 1989ab). Person A’s earnings consisted of two levels: \$1,800 and \$3,600 (monthly gross earnings before taxes and extra charges). The exact values were established by converting the median weekly earnings for each of the two occupations (cashier and social worker) as reported in the U.S. Bureau of Labor Statistics. ${ }^{5}$

\footnotetext{
${ }^{4}$ Although a college degree is required to be a social worker in many U.S. states, a high school diploma with certification is allowed in other states. Thus, education and occupation in our design do not constitute an implausible combination.

${ }^{5}$ Weekly earnings of wage and salary workers by occupation and industry from U.S. Bureau of Labor Statistics, 2020, https://www.bls.gov/cps/earnings.htm\#occind
} 
We also contend that a key normative boundary demarcating whether Person A should or should not negotiate for a higher salary is Person B's earnings, which workers do anchor on and reference (Sauer et al. 2021, p. 943-946). Following Elster (1989ab), wage (in)equality between A and B should motivate how respondents evaluate and judge Person A's economic standing, regardless of Person A's earnings and occupation (Jasso and Webster 1999). When Person A earns the same as Person B, we expect proscriptions of wage negotiation (especially in the absence of information about Person B’s salary). But when Person B earns more than Person A, we anticipate stronger prescriptions of wage negotiation (Jasso and Rossi 1977). We thus manipulate three levels of Person B’s earnings: (1) no information provided to respondents (i.e., Person A does not know Person B’s earnings), (2) Person B earns the same amount as Person A, and (3) Person B earns 30\% more than Person A (i.e., \$2,340 or \$4,680). ${ }^{6}$

Population of vignettes. With the vignette dimensions and levels outlined in Table 1, we constructed the factorial object universe or vignette population (i.e., all possible combinations of dimensions and levels). The number of possible vignettes $(V)$ is $2^{12} \times 3^{1}=12,288$. Since all possible vignettes were plausible and logical, the resulting factorial object universe did not result in impossible combinations of dimensions and levels. We, as a result, retained the full population of 12,288 vignettes.

Drawing vignette samples. With respect to the number of vignettes to present to respondents, the methodological literature suggests that respondents should evaluate no more than ten vignettes to avoid cognitive overload, fatigue, and learning effects (Auspurg and Hinz 2015). While evaluating more than one vignette increases statistical efficiency and power (Jasso 2006), the assumption of temporal stability and causal transience must be maintained. We

\footnotetext{
${ }^{6}$ We selected the value of 30 percent since opinions, attitudes, and behaviors tend to change in reference to this value (Andreoni et al. 2021; Centola et al. 2018).
} 
observe statistical support this assumption (see the Supplemental Materials online). We thus restrict the number of vignettes evaluated per respondent to ten.

We used a simple random design to assign vignette dimensions and levels to respondents, where vignettes were randomly drawn with replacement from the vignette object universe. ${ }^{7}$ Given the respondent sample size $(N=707)$, the size of the vignette object universe $(V=$ 12,288), the total number of vignettes evaluated per respondent $(n=10)$, and the random sampling procedure, 43.58 percent of all possible vignettes were assessed by respondents. ${ }^{8}$

\section{The Evaluation Tasks}

Ten vignettes were presented successively to each respondent at the end of a web-based survey. Prior to assessing the vignettes, respondents were shown a coversheet providing details about Person A, Person B, and the task at hand:

"We will show you 10 scenarios. For each scenario, imagine that there are two people who work for the same employer, Person A and Person B. Each scenario will have the same structure. But each scenario will have different details. When you read each scenario, use all of the details to make judgements about Person A. Please answer the questions after each scenario as best as you can."

A vignette is presented below as an illustration:

"Person A is a 30-year-old black woman with a high school diploma who works as a social worker and has little job experience. Person A's monthly gross earnings total \$1,800 (before taxes and extra charges). Person B is a 50-year-old white man with a college degree who works as a social worker and has a lot of job experience. Person A does not know Person B's monthly gross earnings."

\footnotetext{
${ }^{7}$ We used a simple random design because it is less susceptible to aliasing than fractional factorial designs or $D$-efficient designs (Alexander and Becker 1978; Atzmüller and Steiner 2010; Auspurg and Hinz 2015; Dülmer 2007). According to Dülmer (2016: 340), “One strength of simple random designs is their low susceptibility to systematic biases as might be caused for fractional factorial designs and for $D$ efficient designs by their aliasing structure.” We nevertheless assume that confounding of main effects with higher-order interaction effects is negligible in our study. This is a reasonable assumption to make given the literature on wage negotiations.

${ }^{8}$ One respondent evaluated the same vignette twice.
} 
After respondents read each scenario, they were shown two evaluation tasks: one assessing fairness of earnings and another evaluating personal normative beliefs. We included a measure of fairness of earnings to control for justice evaluations, which may confound the relation between status groups, earnings, and social norms (Auspurg et al. 2017). Since fairness evaluations and social norms range in polarity, respondents were asked to judge each attitude with a 7-point bipolar scale. Instead of showing respondents a horizontal rating scale with all seven response values, we employed a branching technique to simplify the complex decisions tasks (Schaeffer and Dykema 2020).

For fairness of earnings, we asked respondents "Are the monthly earnings of Person A fair, or unfairly high or low?” Respondents were then shown an initial five-option question (Unfairly low, Fair, Unfairly high, Don't know, and Prefer not to say). After selecting one of the endpoints, respondents were shown three levels of intensity: "To what extent are Person A's monthly gross earnings [unfairly low | unfairly high]?”, with Extremely low (high), Moderately low (high), Not at all low (high), and Prefer not to say as response options $(M=2.34, S D=1.59$, $N=6,421, \min =0, \max =6)$. The 7-point scale ranges from unfairly low $(0=$ extremely low, 1 $=$ moderately low, $2=$ not at all low $)$ to fair (3) to unfairly high $(4=$ not at all high, $5=$ moderately high, 6 = extremely high).

For personal normative beliefs, we asked respondents "Should Person A negotiate for a higher salary?” Respondents were then shown an initial five-option question (Should not, Neutral, Should, Don't know, and Prefer not to say). After selecting one of the endpoints, respondents were shown three levels of intensity: "How strong is your belief that Person A [should not | should] negotiate for a higher salary?”, with Not strong at all, Moderately strong, Extremely strong, and Prefer not to say as response options $(M=3.64, S D=1.96, N=6,499$, 
$\min =0, \max =6)$. The 7 -point scale ranges from should not negotiate $(0=$ not at all strong, $1=$ moderately strong, 2 = extremely strong) to neutral (3) to should negotiate $(4=$ not at all strong, 5 = moderately strong, 6 = extremely strong).

We thus measured social norms as "personal normative beliefs” (Bicchieri 2016), or the extent to which individuals believe that others should (or ought to) follow a rule under various circumstances. We selected personal normative beliefs as our operationalization of social norms for two reasons. First, personal normative beliefs, along with empirical and normative expectations, undergird most social norms (Bicchieri 2006). Although some types of social norms exist in the absence of personal normative beliefs, most scholars of social norms contend that evaluations and judgments about what others ought to or ought not to do are core features of a social norm (Gibbs 1965; Hechter and Opp 2001; Opp 2013; Williams 1968). As Hechter and Opp (2001) write: “the most common element in [definitions of a social norm] is 'oughtness' (p. 403)." Second, it is common for scholars of social norms to measure personal normative beliefs in FSEs (Diefenbach and Opp 2007; Jasso and Opp 1997; Robbins et al. 2022), especially as bipolar scales probing degrees of “oughtness”.

\section{Measuring the Character of a Norm: Averages, Dispersion, and Multilevel Models}

Polarity. Following the norms literature (Jasso and Opp 1997; Rauhut and Winter 2010; Robbins et al. 2022), we differentiated between nonexistent, proscriptive, prescriptive, and bipolar norms. If a respondent assigns a rating of 3 (neutral rating) to all evaluated vignettes, we interpreted this as a "nonexistent" norm for that individual. That is, the respondent did not subscribe to a proscriptive, prescriptive, or bipolar wage negotiation norm. If a respondent's ratings include neutral values and values less than 3 , then we interpreted this as a proscriptive norm. Conversely, we identified a prescriptive norm when a respondent's ratings include neutral 
values of 3 and values greater than 3. If a given respondent's ratings include values greater than 3 for some vignettes and less than 3 for other vignettes, then we interpreted this as a bipolar norm.

Conditionality. We also differentiated between unconditional and conditional norms. If a respondent assigns the same non-neutral rating to all evaluated vignettes, then the respondent's norm was interpreted as unconditional (e.g., a rating of 1 for all ten vignettes). In all other cases, the norm was treated as a conditional norm.

Intensity. We assess the intensity of an individual's norm by calculating the numerical “distance” of each rating from the neutral value of 3 (e.g., a rating of 3 would generate a distance of 0 , a rating of 2 would generate a distance of 1 , a rating of 5 would generate a distance of 2 , etc.). We then estimate an individual-specific mean of the distances. For instance, a respondent who subscribes to a prescriptive norm with an individual-specific mean of 2.50 would have a greater intensity (or a stronger devotion to the norm) than a respondent with an individualspecific mean of 0.25 . Finally, we take an average of the individual-specific means to estimate the intensity of the norm of wage negotiations in the population for each type of norm (e.g., unconditional proscriptive norm, conditional prescriptive norm, etc.). In this sense, measures of intensity will always be greater than 0 but less than or equal to 3, where higher values equal greater intensity. ${ }^{9}$

Consensus. To assess consensus, we first summarize the proportion of respondents who vary in the polarity and conditionality of the norm. If some respondents subscribe to conditional prescriptive norm while others subscribe to an unconditional proscriptive norm, then there is

\footnotetext{
${ }^{9}$ Note that it is difficult to differentiate intensity from measurement error or response style. We, as a result, assume that measurement error and response biases are minimal. This is a reasonable assumption to make given our experimental design and survey format.
} 
disagreement over the norm. But if all respondents subscribe to an unconditional proscriptive norm of similar intensity, then there is consensus regarding the norm. Heterogeneity of acceptance characterizes the first example, while homogeneity of acceptance describes the second example (Rauhut and Winter 2010). Statistical estimates of consensus quantify the degree of respondent heterogeneity in normative judgments (Jasso 2006).

Following Jasso (2006), we quantified the degree of consensus by estimating random intercept and random slope hierarchical linear models (HLM), and compared these models to models in which random intercepts and/or random slopes were fixed, or constrained to zero (see Robbins et al. 2022). Improvements to model fit would suggest that respondents differed in their “mean” views of the norm of wage negotiations (i.e., random intercept) and that respondents differed in their views of the circumstances demarcating the norm of wage negotiations (i.e., random slopes). Lack of statistical improvements to model fit would suggest sample homogeneity in intercepts and slopes, indicating consensus among respondents in their views of the norm of wage negotiations. Thus, standard deviations of the random effects provide metrics for the degree of consensus about the norm of wage negotiations.

If random intercepts and/or random slopes were observed, then the next step is to investigate which subpopulations accounted for the random variation in intercepts and/or slopes (Jasso 2006). To do this statistically, we estimated models in which age, race, gender, and SES predicted random intercepts and random slopes (i.e., cross-level interaction effects). The final step is to identify whether within group differences (or variances) are the same for each subpopulation (e.g., male respondents have greater or lesser consensus than female respondents). To do this, we visualize density plots of individual-specific mean ratings of wage negotiations across demographic groups. 
We thus estimated a series of nested two-level HLMs with robust standard errors and a first-order autoregressive residual structure, in which $i$ vignettes $(i=1, \ldots, 10)$ were nested within $j$ individuals $(j=1, \ldots, 700)$. We chose to model our 7-point dependent variable within a linear framework. This was done for a number of reasons. First, linear models are easier to interpret than ordered logit models, especially for higher-order interaction terms. Second, HLM fitted values produced estimates near the lower and upper bounds of the dependent variable (0 and 6 respectively). Third, we found little to no difference in estimates of main effects from linear and ordered logit regression models. The statistical models we estimated along with various tests of modeling assumptions are in the Supplemental Materials online.

\section{Results}

The Character of the Norm of Wage Negotiations: Polarity, Intensity, Conditionality, and Consensus

Of the 707 respondents in our sample, slightly under 1 percent (7 respondents) did not rate any of the vignettes, and slightly over 31 percent (221 respondents) rated between one and nine vignettes. Our analyses use all available data, and include respondents who rated ten or fewer vignettes by answering “don’t know” or “prefer not to say” $(N=6,499)$.

Polarity of the norm of wage negotiations. 1.57 percent of the respondents did not subscribe to a wage negotiations norm by providing neutral ratings of 3 for all evaluated vignettes (see Table 2). In contrast, 30.15 percent of the respondents subscribed to a prescriptive norm, and 1 percent subscribed to a proscriptive norm. A majority of the sample endorsed a bipolar norm of wage negotiations: 67.29 percent of the respondents vacillated between 
proscribing and prescribing wage negotiations as a result of Person A's and Person B's changing characteristics. ${ }^{10}$

Conditionality of the norm of wage negotiations. Beyond the 67.29 percent of respondents who subscribed to a bipolar norm — which is a conditional norm by definition27.28 percent of the respondents subscribed to a conditional proscriptive norm or a conditional prescriptive norm, for a total of 94.57 percent. Altogether, the norm of wage negotiations in the United States is overwhelmingly conditional.

Intensity of the norm of wage negotiations. The norm of wage negotiations is intense among respondents who subscribed to an unconditional norm, as they were relatively far from the neutral rating. For unconditional proscriptive norms $(N=1)$, the average distance (of the individual-specific mean rating) from the neutral value was 2.00, while the average distance was 2.50 for unconditional prescriptive norms $(N=26)$. The small number of respondents (3.85 percent) who subscribed to an unconditional norm favored extreme values, and the level of intensity was statistically stronger for prescriptive norms than proscriptive norms, $b=0.500, S E$ $=0.114, p<.001 .^{11}$

Among conditional norms, the average distance was 0.86 for conditional proscriptive norms $(N=6)$ and 1.40 for conditional prescriptive norms $(N=185)$. The intensity of the norm of wage negotiations was statistically equivalent for respondents who subscribed to either a conditional proscriptive or prescriptive norm, $b=0.537, S E=0.396, p=.176 .{ }^{12}$ For individuals who subscribed to a bipolar wage negotiations norm $(N=471)$, the average distance was 1.83 , or moderately intense ratings.

\footnotetext{
${ }^{10}$ Robustness checks confirmed that respondents who uniformly proscribed or prescribed wage negotiations did not randomly receive ten vignettes that were (un)favorable to wage negotiations.

${ }^{11}$ Results from an OLS regression with cluster-robust standard errors by individuals $(N=27, n=270)$.

${ }^{12}$ Results from an OLS regression with cluster-robust standard errors by individuals $(N=191, n=1,778)$.
} 
Taken together, the majority of the sample subscribed to a bipolar wage negotiations norm where the average level of intensity was between "not at all strong” and "moderately strong”. The patterns in the data thus indicate that the overall intensity of the wage negotiations norm was low-to-moderate.

Consensus about the norm of wage negotiations. The analysis of polarity, conditionality, and intensity indicates disagreement among respondents (see Figure A1 in the Appendix for histograms of individual-specific mean ratings of the norm of wage negotiations by norm type). To investigate consensus formally, we estimated the two-level HLMs outlined above. A likelihood ratio test rejected a model of fixed intercepts and slopes for each vignette dimension in favor of random intercepts and fixed slopes, $\chi^{2}(1)=583.06, p<.001$. In addition, significant variation was observed around the intercept as indicated by the level-2 error term, $S D$ (intercept) $=0.793$. This indicates differences across individuals in their tendencies to proscribe or prescribe wage negotiations, thereby demonstrating respondent heterogeneity and a lack of normative consensus (Jasso 2006). ${ }^{13}$

Next, we relaxed the assumption of fixed slopes, so that each respondent had a unique intercept and a unique slope for each vignette dimension. A model in which all random slopes were freely estimated failed to converge. To assess consensus of the conditions demarcating the norm of wage negotiations, we conducted a series of likelihood ratio tests in which each vignette dimension for Person A and Person B was freely estimated separately. We, for instance, estimated a model in which the genders of Person A and Person B were freely estimated, followed by a separate model in which the races of Person A and Person B were freely estimated.

\footnotetext{
${ }^{13}$ A null HLM yielded a low intra-class correlation (ICC) of .151. The ICC tells us that 15.1 percent of the variation in the norm of wage negotiations occurred between individuals, while 84.9 percent of the variation was within individuals; suggesting that ratings of vignettes by the same individual tended to be different.
} 
The results of a likelihood ratio test rejected a model of random intercepts and fixed slopes in favor of both random intercepts and random slopes for most vignette dimensions, namely the education, experience, occupation, and earnings of Person A and Person B. ${ }^{14}$ Likelihood ratio tests in which the gender, race, age, and occupation of Person A and Person B were freely estimated showed that freed-slopes were not a statistical improvement over fixed-slopes. ${ }^{15}$ These results indicate that respondents differed with one another in their tendencies to proscribe or prescribe wage negotiations and respondents placed different weights on some circumstances demarcating the norm of wage negotiations. Thus, there is disagreement among the respondents over the norm of wage negotiations.

\section{The Circumstances Demarcating the Norm of Wage Negotiations}

We now investigate respondents’ views about which circumstances demarcate, or serve as boundaries of, the norm of wage negotiations. Figure 1 presents results of two-level HLMs in which random slopes were fixed. For both models, we show unstandardized coefficients and their respective 95\% CIs (with robust standard errors and a first-order autoregressive residual structure). In model 1, we observed strong and weak statistical support for the vignette dimensions. Some status groups affected views of wage negotiation as expected: the greater the age, education, and experience of Person A, the more prescriptive the norm of wage negotiations. Interestingly, these effects reversed for Person B: the greater the age, education, and experience of Person B, the more proscriptive the norm of wage negotiations. As expected, occupational status also affected the norm of wage negotiations: prescriptions to negotiate for a higher salary

\footnotetext{
${ }^{14}$ Education, $\chi 2(2)=6.33, p<.05$; experience, $\chi 2(2)=28.30, p<.001$; earnings, $\chi 2(3)=114.30, p<$ .001 .

${ }^{15}$ Gender, $\chi 2(2)=0.35, p=.838$; Person A's race, $\chi 2(1)=0.00, p=1.000$; Person B's race, $\chi 2(1)=0.00$, $p=1.000$; age, $\chi 2(2)=1.20, p=.548$; occupation, $\chi 2(1)=0.62, p=.430$.
} 
were stronger for higher occupational statuses (social worker vs. cashier). Other status groups, namely nominal social categories like the gender and race of Person A and Person B, yielded statistically non-significant results.

For earnings, our results followed previous research (Elster 1989ab): the greater the monthly salary of Person A (\$3,600 vs. \$1,800), the more proscriptive the norm of wage negotiations (a statistically significant effect). This implies that prohibitions against wage negotiations are stronger for higher earning individuals. We also found that respondents anchored on Person B's earnings (a statistically significant familywise effect, $\chi 2(2)=325.94, p<$ .001). When Person B earns the same monthly salary as Person A, respondents proscribed wage negotiations (in relation to the referent category, or no information about Person B's monthly salary). Conversely, when Person B earns 30\% more than Person A, respondents prescribed wage negotiations. This earnings inequality finding is the strongest effect observed in the model. Finally, we found that most vignette dimensions attenuate in magnitude when controlling for fairness of earnings (Figure 1, model 2). But fairness does not entirely confound the effects of the vignette dimensions on the norm of wage negotiations.

Overall, our experimental design and sample simultaneously supports and refutes prior work. We do not find that there is a societal norm favoring increased negotiations for women over those for men (Exley et al. 2020), or a norm favoring one racial group over another. What we do find is that categorical status distinctions involving age, education, experience, and occupational status demarcate who should or should not negotiate for a higher salary (Sauer et al. 2021). And, even more interesting, the categorical status distinctions of age, education, and experience yield countervailing effects depending on who possesses these characteristics: the negotiator (Person A) or the reference point (Person B). Finally, the magnitude of Person A's 
earnings, as well as the (in)equality of earnings between Person A and Person B strongly dictates whether an individual should or should not enter wage negotiations (Elster 1989ab).

Table 3 reports select linear predictions (and 95 percent CIs) by profiles of Person A’s and Person B’s categorical status distinctions (rows 1, 2, and 3) and earnings (columns 1 through 4) calculated from Figure 1, model 1 estimates. Starting with a high-status profile for Person A (i.e., male, White, 50 years old, BA, and social worker) and a low-status profile for Person B (i.e., female, Black, 30 years old, and HSD), respondents prescribed wage negotiations to the greatest extent (a linear prediction of 6.064 or “extremely strong”) when Person A earned \$1,800 month and Person B earned 30\% more than Person A. With these status profiles, respondents always prescribed wage negotiations regardless of variation in Person A’s and Person B's earnings.

Only when Person A was low status and Person B was high status did respondents proscribe wage negotiations. With these two status profiles, respondents proscribed wage negotiations to the lowest extent— "not at all strong” (a linear prediction of 1.967)—when Person A earned \$3,600 a month and Person B earned the same as Person A. When Person A and Person B were both high status, respondents prescribed wage negotiations regardless of variation in Person A’s and Person B’s earnings. Taken together, the linear predictions illustrate how strong the average treatment effects of the circumstances were in motivating respondents to proscribe and prescribe wage negotiations.

Next, we relaxed the assumption of fixed slopes to investigate which vignette dimensions varied in their magnitude. Figure 2 presents boxplots of best linear unbiased predictions of random slopes. These linear predictions were derived from models in which random slopes for each vignette dimension of Person A and Person B were estimated separately. Of the status 
group differences, only the effect of Person B's experience varied to a great extent between respondents, with some estimates slightly positive (most being negative). For the remaining status group differences, there were varying amounts of disagreement, which tended to increase for statistically significant vignette dimensions (e.g., Person A's and Person B’s education).

In contrast, the earnings dimensions varied to a great degree between respondents in their effects on the norm of wage negotiations. As Figure 2 shows, most respondents proscribed wage negotiations (to varying degrees) when Person A earned \$3,600 a month (vs. \$1,800 a month), while a small minority of respondents (roughly an eighth) prescribed wage negotiations under the same conditions. Similar dynamics were observed for Person B earning the same monthly salary as Person A, while all respondents prescribed wage negotiations (with some heterogeneity of acceptance) when there was an inequality in earnings between Person A and Person B.

In short, categorical status differences and the earnings of Person A and Person B served as boundaries between who should and should not negotiate for a higher salary. Moreover, circumstances demarcating the norm of wage negotiations exhibited more consensus in some cases (e.g., age, education, and occupation) and less consensus in others (e.g., experience and earnings). Overall, however, we observed relatively little consensus.

\section{Consensus Within and Between Subpopulations: Age, Race, Gender, and SES}

In the next subsection, we identify whether individual-level tendencies to proscribe or prescribe wage negotiations are a function of the age, race, gender, and SES of respondents. After that, we investigate whether variation in the weights placed on the circumstances driving the norm of wage negotiations is a function of the age, race, gender, and SES of respondents.

The character of the norm of wage negotiations within and between subpopulations. We now present estimates from a two-level HLM that includes the age, race, gender, and SES of 
respondents as predictors of normative differences. The model, in Table 4, controlled for vignette dummies, vignette dimensions, and the individual-level control variables outlined in the Data and Methods section. These results show that classic demographic characteristics yield statistically non-significant effects. Next, we investigate whether within-group variation was the same between subpopulations (e.g., consensus is greater or lesser among White respondents than nonWhite respondents). In Figure 3, kernel density plots of individual-specific mean ratings of the norm of wage negotiations revealed that the amount of disagreement (or lack of consensus) within subpopulations was comparable between subpopulations (e.g., disagreement among White and non-White respondents was comparable). In short, classic demographic groups did not vary in their tendencies to proscribe or prescribe wage negotiations, and the amount of disagreement (or lack of consensus) within groups was comparable between groups.

The circumstances demarcating the norm to marry between subpopulations. Earlier, we found that some circumstances demarcating the norm of wage negotiations exhibited greater disagreement than other circumstances. We next investigate how much classic demographic groups account for this disagreement by estimating a series of two-level HLMs with cross-level moderation in which the age, race, gender, and SES of respondents interacted with each vignette dimension separately. These models controlled for vignette dummies and the individual-level control variables outlined in the Data and Methods section.

Note that our interest here is not with the direction of effects, but with whether classic demographic characteristics account for variation in the random slopes. Following from this logic, Table 5 details which demographic characteristics yield statistically (non)significant crosslevel interact effects. Table 5 shows that the majority of cross-level interactions are statistically non-significant, suggesting that demographic groups interpret the boundaries of the norm of 
wage negotiations similarly; that is, we find limited social cleavages along demographic lines in evaluations of the circumstances demarcating the norm of wage negotiations. There are, however, some exceptions. The age and gender of respondents appear to generate the greatest number of cross-level interactions (i.e., four), while all other demographic groups yield statistically significant interactions—albeit inconsistent across demographic groups—with zeroto-two vignette dimensions. Overall, we found that classic demographic groups place different levels of importance on how some circumstances affect the norm of wage negotiations. Most circumstances, however, yielded relatively consistent effects regardless of the age, race, gender, and SES of respondents.

\section{Discussion and Conclusion}

Many scholars claim that the moral economy and wage bargaining are tightly coupled. In this article, we have sought to understand whether a norm of wage negotiations exists in the United States, and, if so, what the character of this norm might look like. Our FSE is uniquely positioned to map the character of this norm because we were able to exogenously manipulate various counterfactual conditions that demarcate, or serve as boundaries of, the norm of wage negotiations.

In terms of key findings, we first demonstrate that a norm of wage negotiations exists in the U.S. moral economy. The vast majority of individuals follow a norm, while a small minority believe that wage bargaining is not governed by informal rules. We do, however, find that the norm of wage negotiations is fairly weak: it is largely bipolar, conditional, and of a low-tomoderate intensity, with disagreement over the norm as well as circumstances demarcating the norm. Despite normative disagreement, two types of norm followers predominate in the United States: those who prescribe wage negotiations regardless of the conditions (prescriptive norm), 
and those who vacillate between prescribing and proscribing wage negotiations depending on the conditions (bipolar norm).

Second, we fail to observe deep social cleavages along demographic lines. The character of the norm of wage negotiations_-and the conditions serving as boundaries of —are comparable across demographic groups. The young and the old, men and women, Whites and non-Whites, and low- and high-SES individuals tend to agree on the norm of wage negotiations. What appears to drive variation in the norm of wage negotiations are the characteristics of individuals and circumstances under evaluation, not the status group distinctions of those individuals doing the evaluating.

Third, we discover that key conditions prompt the approval and disapproval of wage negotiations: when (1) the focal actor is a high-status employee who (2) has a low salary and (3) works with a low-status colleague (or reference point) who (4) earns more than the focal actor, respondents approve of (or prescribe) wage negotiations. Again, we find that the magnitude of these conditions is comparable across demographic groups.

\section{Implications}

Our findings have important implications for scholarship in the areas of moral economy, wage negotiations, and social norms. At first glance, our findings might suggest that a moral economy of wage negotiations is alive and well in the United States. Only a small minority of individuals are unwilling to state whether others should or should not negotiate for higher wages, suggesting a nonexistent norm. The remaining 98.43 percent of individuals subscribe to a norm. Upon deeper inspection, however, we find that the nature of the norm is conditional and does not exhibit consensus. Even for a classic condition known to spark wage negotiations, like the inequality of earnings, there is heterogeneity of acceptance, with treatment effects ranging from 
0.052 to 1.331 (see Figure 2). This all implies that views of wage negotiations are not standardized or uniform in the United States. The moral economy of wage negotiations cannot be understood as “a popular consensus about legitimate and illegitimate practices” of wage bargaining (Sachweh 2012:422). What are the implications of these differences of opinion? Under conditions of mass disagreement, individuals are prone to bargaining, conflict, and debate (Coleman 1990). Such conflict will play out over who and why people should or should not negotiate for higher wages. Although we cannot track change over time, our findings support Western and Rosenfeld's (2011) main finding: there has been an erosion of the distributional norms underlying the U.S. moral economy.

A second major contribution of our analysis is to gain insight into how status groups and earnings inequalities are linked to the norm of wage negotiations. Sauer et al. (2021) find that categorical status distinctions determine who enters negotiations, as well as the magnitude of economic returns. The authors, in particular, show that women are less likely to enter wage negotiations than men. And when they do negotiate, the wages of women do not appear to improve. In our study, categorical status distinctions are features of the situation that serve as boundaries of the norm of wage negotiations. We find that the norm is independent of some status groups, namely the gender and race of hypothetical employees under evaluation. We also find that respondents' age, race, gender, and SES do not account for between-individual variation in the norm of wage negotiations. This set of findings underscores how weakly tied gender is to the norm of wage negotiations, contrary to Exley et al. (2020). By showing that the link between gender and wage negotiations is not normative in the United States, we are able to rule out a key channel through which the gender gap in pay persists. Instead, the inequality of earnings between men and women is likely a function of discrimination (Tomaskovic-Devey and Avent-Holt 
2019), shared cultural beliefs about gender (Ridgeway 2011), and status differences in claimsmaking (Sauer et al. 2021). That being said, other status distinctions are important determinants of who should or should not negotiate for a higher salary. These include the age, experience, education, and occupation of employees.

Third, our analysis contributes to the literature on social norms by demonstrating the utility of the multidimensional approach to mapping social norms. For decades, scholars of social norms have pushed for the widespread use of measurement tools that properly measure polarity, conditionality, intensity, and consensus (Grigoryeva and Robbins 2021; Jasso and Opp 1997; Rauhut and Winter 2010; Robbins et al. 2022). These tools, however, are time consuming and costly for general population surveys and laboratory experiments since they require respondents to assess a systematic set of counterfactual conditions. When done properly, however, they yield deep understandings into the dynamics of social protest (Jasso and Opp 1997), bridewealth (Horne et al. 2018), inequality (Rauhut and Winter 2010), and marriage (Robbins et al. 2022). Our study builds on this literature by providing novel empirical support for the idea that the norm of wage negotiations is decoupled from the U.S. moral economy. A finding that would have been difficult to discover without our novel FSE.

\section{Limitations and Directions for Future Research}

Our study provides important insights into the innerworkings of the U.S. moral economy, but it is not without limitations. While our dependent variable captures personal normative beliefs, it does not provide evidence about whether individuals would actually sanction norm violators, or evidence about subjective expectations of other people's willingness to follow the norm. Keep in mind that most studies on social norms measure personal normative beliefs (Diefenbach and Opp 2007; Grigoryeva and Robbins 2021; Jasso and Opp 1997; Robbins et al. 
2022), and that many of our findings align with actual selection into wage bargaining (Sauer et al. 2021). While we believe this provides some support for the idea that we are tapping into the concept of social norms, future research would do well to measure other dimensions of the social norm concept, including behavioral and attitudinal measures.

We also recognize limitations to our design. Our FSE excluded a number of circumstances demarcating the norm of wage negotiations, which may have affected estimates of conditionality and consensus. We settled on this design to see whether people approve or disapprove of wage negotiations under commonplace bargaining conditions and to offer a conservative assessment of the moral economy, but other circumstances likely drive views of wage bargaining. It would be useful for future research to investigate the impact of these other circumstances, including market value, job tenure, health status, and job performance (Auspurg et al. 2017). Likewise, because our research questions and design targeted a specific norm, we can say little about other norms that might undergird the moral economy of wage negotiations. For instance, prior research shows that masculinity norms drive behavior in the workplace (Berdahl et al. 2018). Men, as a result, may be more likely to negotiate for higher wages because of these norms, and not the norm of wage negotiations. Investigating the impact of these alternative norms would supply further revelations about the U.S. moral economy.

In conclusion, the present article extends our understanding of the U.S. moral economy in general and the norm of wage negotiations in particular. By using a FSE, the present study unearthed important observations about wage bargaining in the United States. We found that the norm of wage negotiations is weak, that it does not vary across certain demographic groups, and that the relation between categorical status distinctions and views of wage bargaining are causal. With this work, our hope is to help sociologists better understand the norm of wage negotiations, 
and to lay the groundwork for novel measurement tools that ascertain the norms, rules, and values of the moral economy. 
Table A1. Summary Statistics and Descriptions of Variables

\begin{tabular}{|c|c|c|c|c|c|c|}
\hline Name & Definition & Mean & $\mathrm{SD}$ & Min. & Max. & $N$ \\
\hline \multicolumn{7}{|l|}{ Vignette evaluation tasks } \\
\hline Norm of wage negotiations & Should Person A negotiate for a higher salary? & 3.64 & 1.96 & 0 & 6 & 6499 \\
\hline Fairness of earnings & Person A's earnings fair? & 2.34 & 1.59 & 0 & 6 & 6421 \\
\hline \multicolumn{7}{|l|}{ Individual-level variables } \\
\hline Age & Age in years & 46.34 & 16.54 & 18 & 85 & 707 \\
\hline \multicolumn{7}{|l|}{ Race } \\
\hline White (omitted) & Non-Hispanic White & $77.51 \%$ & -.-- & -.- & -.- & 548 \\
\hline Non-White & Non-White & $22.39 \%$ & --- & --- & --- & 159 \\
\hline \multicolumn{7}{|l|}{ Gender } \\
\hline Male (omitted) & Male & $50.92 \%$ & --- & --- & --- & 360 \\
\hline Female & Female & $49.08 \%$ & --- & --- & --- & 347 \\
\hline \multicolumn{7}{|l|}{ Education } \\
\hline High school diploma or lower (omitted) & High school diploma or lower & $37.62 \%$ & -- & --- & -- & 266 \\
\hline Some college & Some college (no degree) or an Associate's degree & $27.58 \%$ & --- & --- & --- & 195 \\
\hline Bachelor's degree or higher & Bachelors, Masters, Professional, or Doctorate degree & $34.79 \%$ & --- & --- & --- & 246 \\
\hline $\ln$ (household income per capita) & & 9.91 & 0.91 & 6.08 & 11.83 & 688 \\
\hline \multicolumn{7}{|l|}{ Individual-level control variables } \\
\hline \multicolumn{7}{|l|}{ Marital status } \\
\hline Never married (omitted) & Never married & $32.81 \%$ & --- & --- & --- & 232 \\
\hline Married & Married & $48.66 \%$ & --- & --- & --- & 344 \\
\hline Formerly married & Widowed, divorced, separated & $18.53 \%$ & --- & --- & -.- & 131 \\
\hline \multicolumn{7}{|l|}{ Cohabitation status } \\
\hline Not cohabiting (omitted) & Not living with a partner & $41.84 \%$ & --- & --- & --- & 295 \\
\hline Presently cohabiting & Presently living with a partner & $58.16 \%$ & --- & --- & --- & 410 \\
\hline \multicolumn{7}{|l|}{ Employment status } \\
\hline Not working (omitted) & Temporarily not working, unemployed, retired, going to school, keeping house, etc. & $43.32 \%$ & -.- & --- & --- & 305 \\
\hline Working full-time & Working full-time & $47.02 \%$ & --- & --- & --- & 331 \\
\hline Working part-time & Working part-time & $9.66 \%$ & --- & --- & --- & 68 \\
\hline \multicolumn{7}{|l|}{ Region } \\
\hline Northeast (omitted) & & $25.18 \%$ & --- & --- & --- & 178 \\
\hline Midwest & & $20.23 \%$ & --- & --- & --- & 143 \\
\hline South & & $40.17 \%$ & --- & --- & --- & 284 \\
\hline West & & $14.43 \%$ & -- & --- & -- & 102 \\
\hline
\end{tabular}



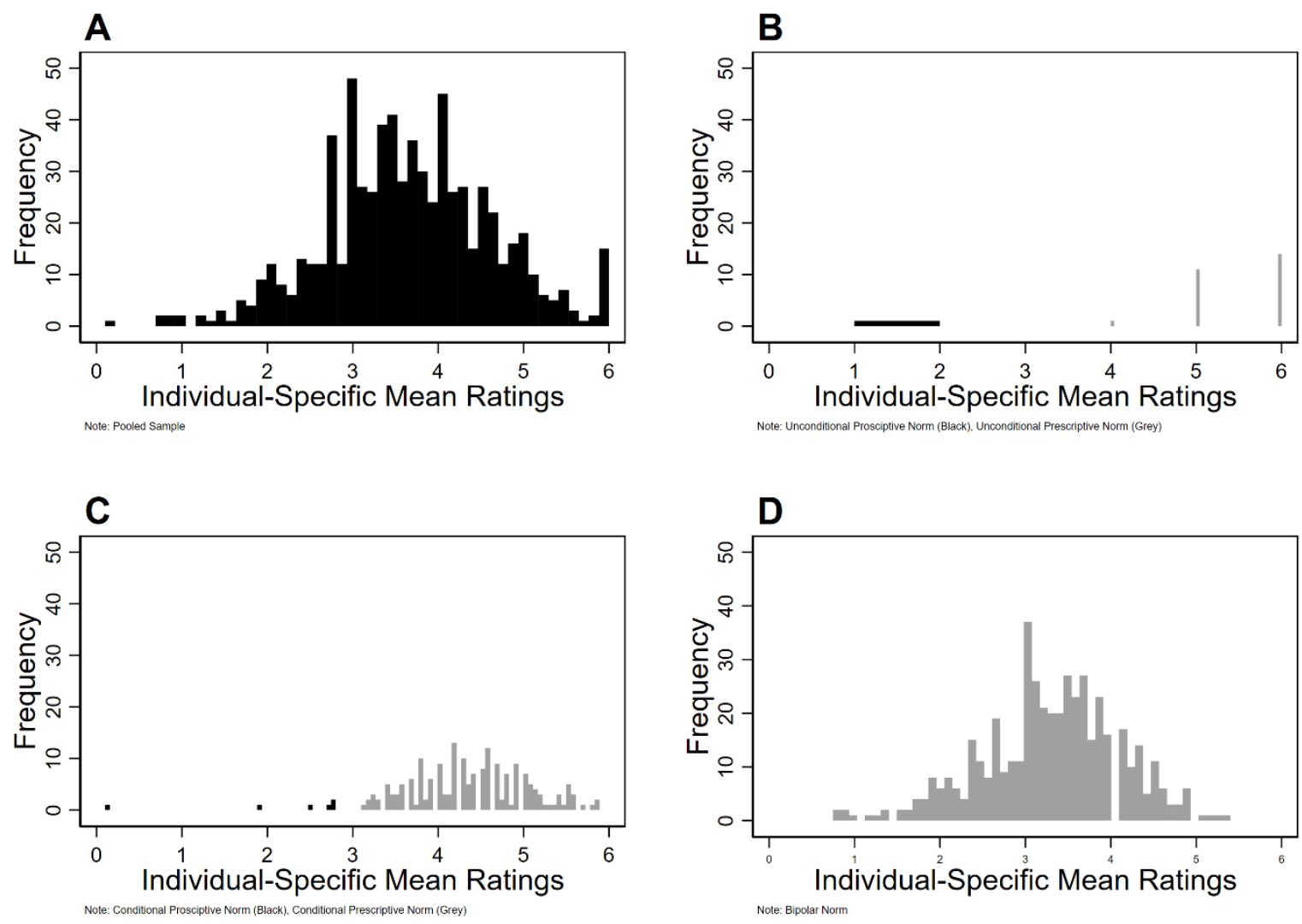

Figure A1. Frequency Distribution of Individual-Specific Mean Ratings of the Norm of Wage Negotiations for the Pooled Sample (Panel A), Unconditional Norms (Panel B), Conditional Norms (Panel C), and Bipolar Norms (Panel D)

Note: In Panels B and C, black distributions indicate a proscriptive norm, grey distributions indicate a prescriptive norm. 


\section{References}

Alexander, Cheryl S., and Henry J. Becker. 1978. "The Use of Vignettes in Survey Research.” Public Opinion Quarterly 42: 93-104.

Andreoni, James, Nikos Nikiforakis, and Simon Siegenthaler. 2021. "Predicting Social Tipping and Norm Change in Controlled Experimnents.” PNAS 118: e2014893118.

Arnold, Thomas C. 2001. "Rethinking Moral Economy.” American Political Science Review 95: 85-95.

Atzmüller, Christiane, and Peter M. Steiner. 2010. “Experimental Vignette Studies in Survey Research.” Methodology 6:128-38.

Auspurg, Katrin, and Thomas Hinz. 2015. Factorial Survey Experiments. Los Angeles, CA: Sage.

Auspurg, Katring, and Annette Jäckle. 2017. "First Equals Most Important? Order Effects in Vignette-Based Measurement.” Sociological Methods \& Research 490-539.

Auspurg, Katrin, Thomas Hinz, and Carsten Sauer. 2017. "Why Should Women Get Less? Evidence on the Gender Pay Gap from Multifactorial Survey Experiments.” American Sociological Review 82: 179-210.

Berdahl, Jennifer L., Marianne Cooper, Peter Glick, Robert W. Livingston, and Joan C. Williams. "Wok as a Masculinity Contest.” Journal of Social Issues 74: 422-448.

Berinsky, Adam J., Michele F. Margolis, and Michael W. Sances. 2014. "Separating the Shirkers from the Workers? Making Sure Respondents Pay Attention on Self-Administered Surveys.” American Journal of Political Science 58: 739-753.

Bicchieri, Cristina. 2006. The Grammar of Society: The Nature and Dynamics of Social Norms. Cambridge University Press.

Bicchieri, Cristina. 2016. Norms in the Wild: How to Diagnose, Measure, and Change Social Norms. Oxford University Press.

Booth, William J. 1994. "On the Idea of the Moral Economy.” American Political Science Review 88: 653-667.

Bureau of Labor Statistics, U.S. Department of Labor, Occupational Outlook Handbook, on the Internet at https://www.bls.gov/cps/demographics.htm, (visited February 11 ${ }^{\text {th }}, 2022$ ).

Card, David, Alexandre Mas, Enrico Moretti, and Emmanuel Saez. 2012. "Inequality at Work: The Effect of Peer Salaries on Job Satisfaction.” American Economic Review 102: 29813003.

Centola, Damon, Joshua Becker, Devon Brackbill, and Andrea Baronchelli. 2018. "Experimental Evidence for Tipping Points in Social Convention.” Science 360: 1116-1119.

Clark, Andrew E., and Andrew J. Oswald. 1996. "Satisfaction and Comparison Income." Journal of Public Economics 61: 359-381.

Coleman, James. 1990. Foundations of Social Theory. Harvard University Press.

Diefenbach, Heike and Karl-Dieter Opp. 2007. "When and Why Do People Think There Should Be a Divorce? An Application of the Factorial Survey.” Rationality and Society 19: 485-517.

Dülmer, Hermann. 2007. “Experimental Plans in Factorial Surveys: Random or Quota Design?” Sociological Methods \& Research 45: 304-347.

Dülmer, Hermann. 2016. "The Factorial Survey: Design Selection and its Impact on Reliability and Internal Validity.” Sociological Methods \& Research 35: 382-409.

Elster, Jon. 1989a. The Cement of Society. Cambridge University Press.

Elster, Jon. 1989b. “Wage Bargaining and Social Norms.” Acta Sociologica 32: 113-136. 
Exley, Chrstine L., Muriel Niederle, and Lise Vesterlund. 2020. "Knowing When to Ask: The Cost of Leaning In.” Journal of Political Economy 128: 816-854.

Fourcade, Marion, and Kieran Healy. 2007. "Moral View of Market Society.” Annual Review of Sociology 33: 285-311.

Gibbs, Jack P. 1965. “Norms: The Problem of Definition and Classification.” American Journal of Sociology 70: 586-594.

Grigoryeva, Maria, and Blaine G. Robbins. 2021. "A Mouthful of Diamonds and a Pocketful of Secrets: Mapping Concealment and its Normative Foundations.” SocArXiv. April 6. doi:10.31235/osf.io/4xwkv.

Hechter, Michael, and Karl-Dieter Opp (eds.). 2001. Social Norms. Russell Sage

Heen, Miliaikeala S. J., Joel D. Lieberman, and Terance Miethe. 2014. "A Comparison of Different Online Sampling Approaches for Generating National Samples.” UNLV Center for Crime and Justice Policy.

Horne, Christine. 2009. The Rewards of Punishment: A Relational Theory of Norm Enforcement. Stanford University Press.

Horne, Christine, and Stefanie Mollborn. 2020. “Norms: An Integrated Framework.” Annual Review of Sociology 46: 467-487.

Horne, Christine, Naa Dodua Dodoo, and F. Nii-Amoo Dodoo. 2018. "The Conditionality of Norms: The Case of Bridewealth.” Social Psychology Quarterly 81: 319-339.

Jackson, Jay. 1966. “A Conceptual and Measurement Model for Norms and Roles.” The Pacific Sociological Review 9: 35-47.

Jasso, Guillermina. 2006. "Factorial Survey Methods for Studying Beliefs and Judgments.” Sociological Methods \& Research 34: 334-90.

Jasso, Guillermina, and Karl-Dieter Opp, 1997. "Probing the Character of Norms: A Factorial Survey Analysis of the Norms of Political Action.” American Sociological Review 62: 947964.

Jasso, Guillermina, and Peter H. Rossi. 1977. "Distributive Justice and Earned Income.” American Sociological Review 42: 639-651.

Jasso, Guillermina, and Murray Webster Jr. 1997. "Double Standards in Just Earnings for Male and Female Workers.” Social Psychology Quarterly 60: 66-78.

Jasso, Guillermina, and Murray Webster Jr. 1999. “Assessing the Gender Gap in Just Earnings and Its Underlying Mechanisms.” Social Psychology Quarterly 62: 367-380.

Katzenstein, Peter. 1985. Small States in World Markets. Cornell University Press.

Krupka, Erin L., and Roberto A. Weber. 2013. "Identifying Social Norms Using Coordination Games: Why Does Dictator Game Sharing Vary?” Journal of the European Economic Association 11: 495-524.

Lewicki, Roy J., David M. Saunders, and Bruce Barry. 2006. Negotiations. McGraw-Hill Irwin.

Mau, Steffen. 2003. The Moral Economy of Welfare States: Britain and Germany Compared. Routledge.

McCall, Leslie. 2001. "Sources of Racial Wage Inequality in Metropolitan Labor Markets: Racial, Ethnic, and Gender Differences.” American Sociological Review 66: 520-541.

Nash, John. 1950. “The Bargaining Problem.” Econometrica 18: 155-162.

Polanyi, Karl. 1944. The Great Transformation: The Political and Economic Origins of Our Time. Bacon Press.

Rauhut, Heiko, and Fabian Winter. 2010. "A Sociological Perspective on Measuring Social Norms by Means of Strategy Method Experiments.” Social Science Research 39: 1181-1194. 
Ridgeway, Cecilia L. 2011. Framed by Gender: How Gender Inequality Persists in the Modern World. Oxford University Press.

Robbins, Blaine G., Aimée Dechter, and Sabino Kornrich. 2022. “Assessing the Deinstitutionalization of Marriage Thesis: An Experimental Test.” American Sociological Review, Forthcoming.

Rossi, Peter H., and Richard A. Berk. 1985. "Varieties of Normative Consensus.” American Sociological Review 50: 333-347.

Rubinstein, A. 1982. "Perfect Equilibria in a Bargaining Model.” Econometrica 50: 97-110.

Sachweh, Patrick. 2012. "The Moral Economy of Inequality: Popular Views on Income Differentiation, Poverty and Wealth.” Socio-Economic Review 10: 419-445.

Saur, Carsten, Peter Valet, Safi Shams, and Donald Tomaskovic-Devey. 2021. "Categorical Distinctions and Claims-Making: Opportunity, Agency, and Returns from Wage Negotiations.” American Sociological Review 86: 934-959.

Schaeffer, Nora Cate. 1991. "Hardly Ever or Constantly? Group Comparisons Using Vague Qualifiers.” Public Opinion Quarterly 55: 395-423.

Schaeffer, Nora Cate, and Jennifer Dykema. 2020. "Advances in the Science of Asking Questions.” Annual Review of Sociology 46: 37-60.

Schelling, Thomas C. 1960. The Strategy of Conflict. Harvard University Press.

Scott, James C. 1976. The Moral Economy of the Peasant: Rebellion and Subsistence in Southeast Asia. Princeton University Press.

Swenson, Peter. 1989. Fair Shares: Unions, Pay and Politics in Sweden and West Germany. Cornell University Press.

Thompson, Edward Palmer. 1971. "The Moral Economy of the English Crowd in the $18^{\text {th }}$ Century.” Past and Present 50: 76-136.

Tilly, Charles. 1999. Durable Inequality. University of California Press.

Tomaskovic-Devey, Donald, and Dustin Avent-Holt. 2019. Relational Inequalities: An Organizational Approach. Oxford University Press.

Wallander, Lisa. 2009. "25 Years of Factorial Surveys in Sociology: A Review.” Social Science Research 38: 505-520.

Williams, Robin M., Jr. 1968. "Values: The Concept of Values.” Pp. 283-287 in International Encyclopedia of the Social Sciences, vol. 16, edited by D. L. Sills. Macmillan. 
Table 1. Vignette Dimensions and Levels

\begin{tabular}{lc} 
Dimensions & Levels \\
\hline Person A Gender & man/woman \\
Person B Gender & man/woman \\
Person A Race & black/white \\
Person B Race & black/white \\
Person A Age & $30 / 50$ years \\
Person B Age & $30 / 50$ years \\
Person A Education & high school diploma/college degree \\
Person B Education & high school diploma/college degree \\
Person A Experience & little/a lot \\
Person B Experience & little/a lot \\
Persons A and B Occupation & cashier/social worker \\
Person A Earnings & $\$ 1800 / \$ 3600$ \\
Person B Earnings & person B's earnings unknown/person B's earnings the same as \\
& person A's earnings/person B's earnings 30\% more than person \\
& A's earnings (i.e., \$2340 or \$4680) \\
\hline
\end{tabular}


Table 2. Polarity and Conditionality of the Norm of Wage Negotiations

\begin{tabular}{lcc}
\hline Norm of Wage Negotiations & Number & \% of Sample \\
\hline Polarity & & \\
Nonexistent $(R=3)$ & 11 & 1.57 \\
Prescriptive $(R>3 ; r \geq 3)$ & 211 & 30.14 \\
Proscriptive $(R<3 ; r \leq 3)$ & 7 & 1.00 \\
Bipolar $(0<R<6 ; R \neq 3 ; 0 \leq r \leq 6)$ & 471 & 67.29 \\
Total & 700 & 100 \\
Conditionality & & \\
Nonexistent $(R=3)$ & 11 & 1.57 \\
Unconditional $(R=r ; r \neq 3)$ & 27 & 3.86 \\
Conditional $(V A R(r) \neq 0)$ & 662 & 94.57 \\
Total & 1777 & 100 \\
\hline
\end{tabular}

Note: Polarity and conditionality are defined by the numerical pattern of each respondent's individual-specific mean $(R)$ of the norm of wage negotiations ratings $(r)$. Polarity: If a respondent assigns a rating of 3 (neutral value) to all $N$ vignettes, this indicates that the respondent does not subscribe to a norm of wage negotiations (nonexistent norm). If all $N$ of a given respondent's ratings are both 3 and greater than 3 , this indicates that the respondent subscribes to a prescriptive norm. If all $N$ of a given respondent's ratings are both 3 and less than 3 , this indicates that the respondent subscribes to a proscriptive norm. If the respondent's ratings span values less than 3 and values greater than 3 , this indicates that the respondent subscribes to a bipolar norm.

Conditionality: if a respondent assigns the same non-neutral (i.e., 3) rating to all $N$ vignettes, this indicates that the respondent subscribes to an unconditional norm; in all other cases, the norm is regarded as a conditional norm. 
Table 3. Select Linear Predictions of the Norm of Wage Negotiations

\begin{tabular}{ccccc}
\multicolumn{2}{c}{ Person A Earns \$1,800 } & & \multicolumn{2}{c}{ Person A Earns \$3,600 } \\
\cline { 1 - 2 } \cline { 5 - 6 } $\begin{array}{c}\text { A Earns Same } \\
\text { as B }\end{array}$ & B Earns 30\% & & A Earns Same & B Earns 30\% \\
More than A & & as B & More than A
\end{tabular}

Person A High Status, Person B Low Status

Person A: Male, White, 50 yrs old, BA

$5.046 \quad 6.064 \quad 4.350$

5.367

Person B: Female, Black, 30 yrs old, HSD $\quad$ (4.833, 5.259) (5.846, 6.282)

$(4.133,4.566) \quad(5.143,5.592)$

Occupation: Social Worker

Person A Low Status, Person B High Status

Person A: Female, Black, 30 yrs old, HSD

Person B: Male, White, 50 yrs old, BA

2.664

3.681

1.967

2.985

Occupation: Cashier

$(2.441,2.886) \quad(3.469,3.893)$

$(1.740,2.194) \quad(2.765,3.204)$

Person A and Person B High Status

Person A: Male, White, 50 yrs old, BA

4.110

5.128

3.413

4.431

Person B: Male, White, 50 yrs old, BA

$(3.898,4.322) \quad(4.913,5.343)$

(3.203, 3.624) (4.214, 4.648)

Occupation: Social Worker

Note : Linear predictions based on model 1 in Figure 1 using the delta method (95 percent CIs in parentheses).

HSD = high school diploma; $\mathrm{BA}=$ college degree. 
Table 4. Consensus of the Norm of Wage Negotiations across

Subpopulations, Two-Level Hierarchical Linear Model

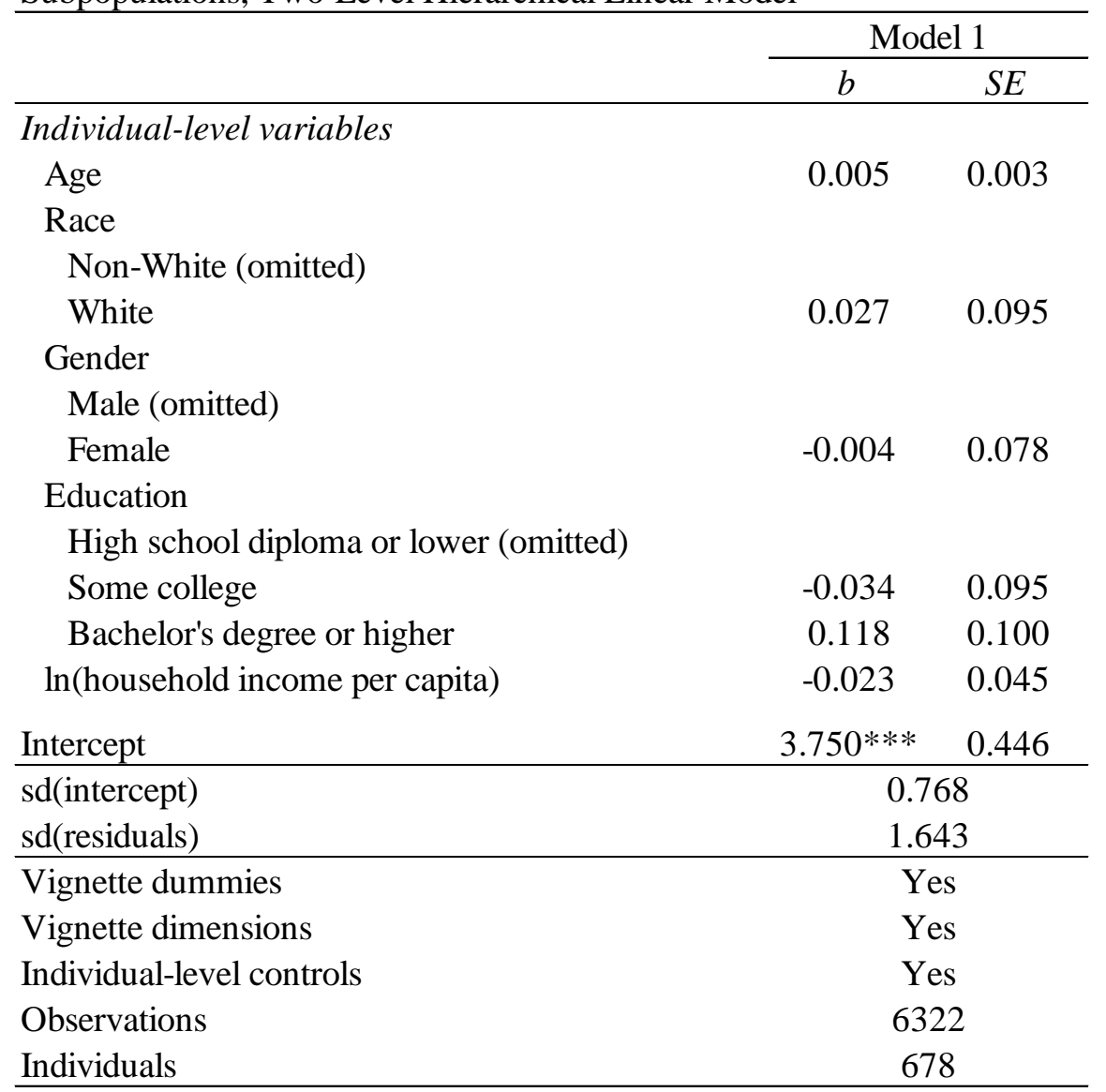

*** $p<0.001, * * p<0.01, * p<0.05$ (two-tailed)

Note $: b=$ unstandardized slopes, $S E$ = robust standard errors. Control

variables included marital status, cohabitation status, employment status, and U.S. region. 
Table 5. Cross-Level Interaction Effects

\begin{tabular}{lccccc}
\hline & $\begin{array}{c}\text { Respondent } \\
\text { Age }\end{array}$ & $\begin{array}{c}\text { Respondent } \\
\text { Gender }\end{array}$ & $\begin{array}{c}\text { Respondent } \\
\text { Race }\end{array}$ & $\begin{array}{c}\text { Respondent } \\
\text { Education }\end{array}$ & $\begin{array}{c}\text { Respondent } \\
\text { Income }\end{array}$ \\
\hline Person A Gender & NS & NS & NS & NS & NS \\
Person B Gender & NS & NS & NS & NS & NS \\
Person A Race & NS & NS & NS & NS & NS \\
Person B Race & NS & NS & NS & NS & NS \\
Person A Age & NS & NS & NS & NS & NS \\
Person B Age & NS & NS & NS & NS & NS \\
Person A Education & NS & NS & - & NS & NS \\
Person B Education & NS & - & - & NS & NS \\
Person A Experience & + & + & NS & NS & NS \\
Person B Experience & NS & - & NS & - & NS \\
Person A and B Occuptation & + & + & NS & NS & NS \\
Person A Earnings & - & NS & NS & NS & NS \\
Person B Earnings & + & NS & NS & - & NS \\
\hline
\end{tabular}

Note: For each model, $N=678, V=6,322$. NS = statistically non-significant at $p>.05$. "+" or "-" indicate statistically significant interaction effect at $p<.05$. Where appropriate, this includes familywise tests of interaction effects. 


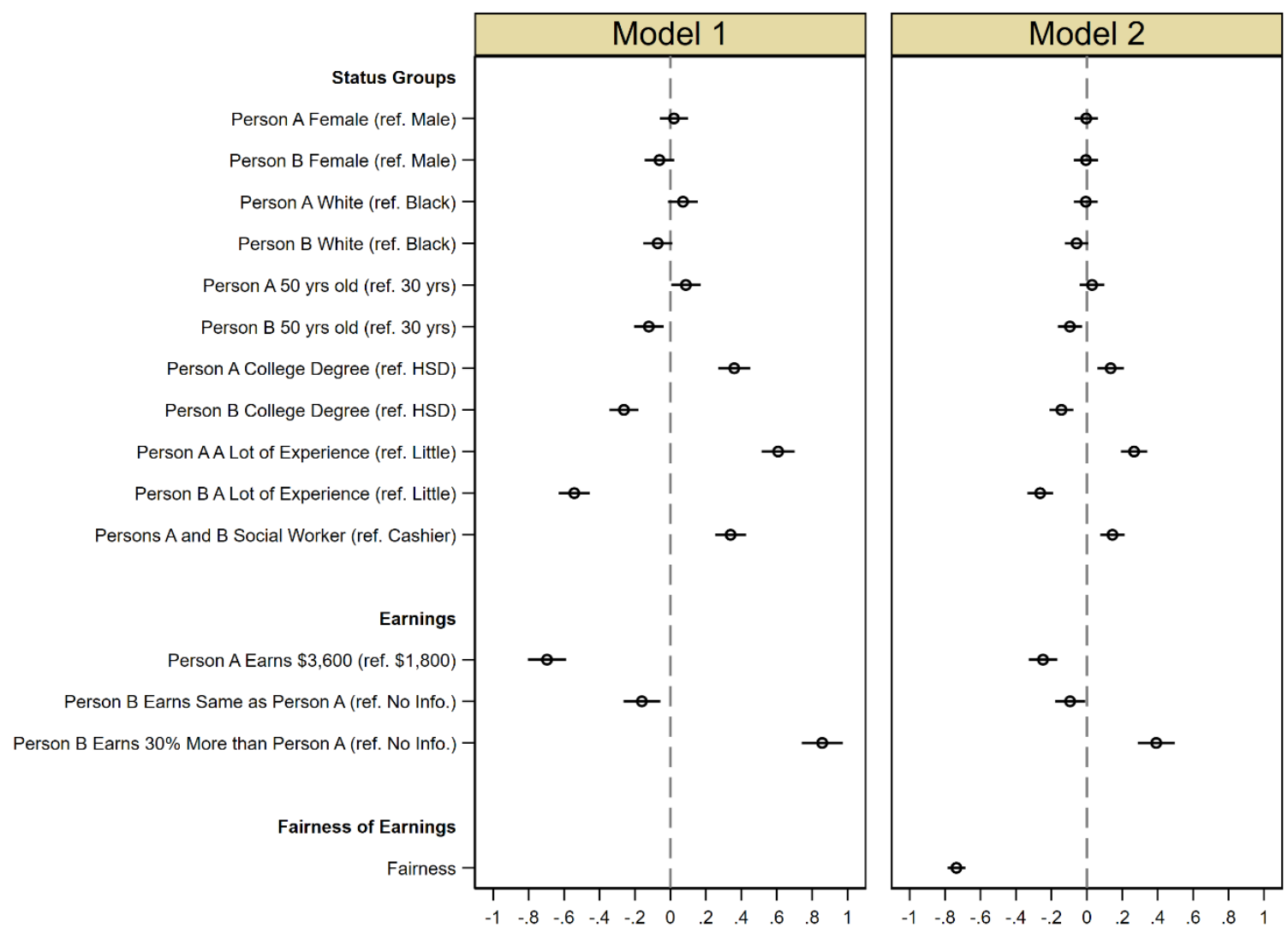

Figure 1. Coefficients of Vignette Dimensions and Fairness of Earnings on the Norm of Wage Negotiations

Notes: Bars around coefficients reflect 95\% CIs. HSD = high school diploma. No Info. = no information about Person B's earnings. 


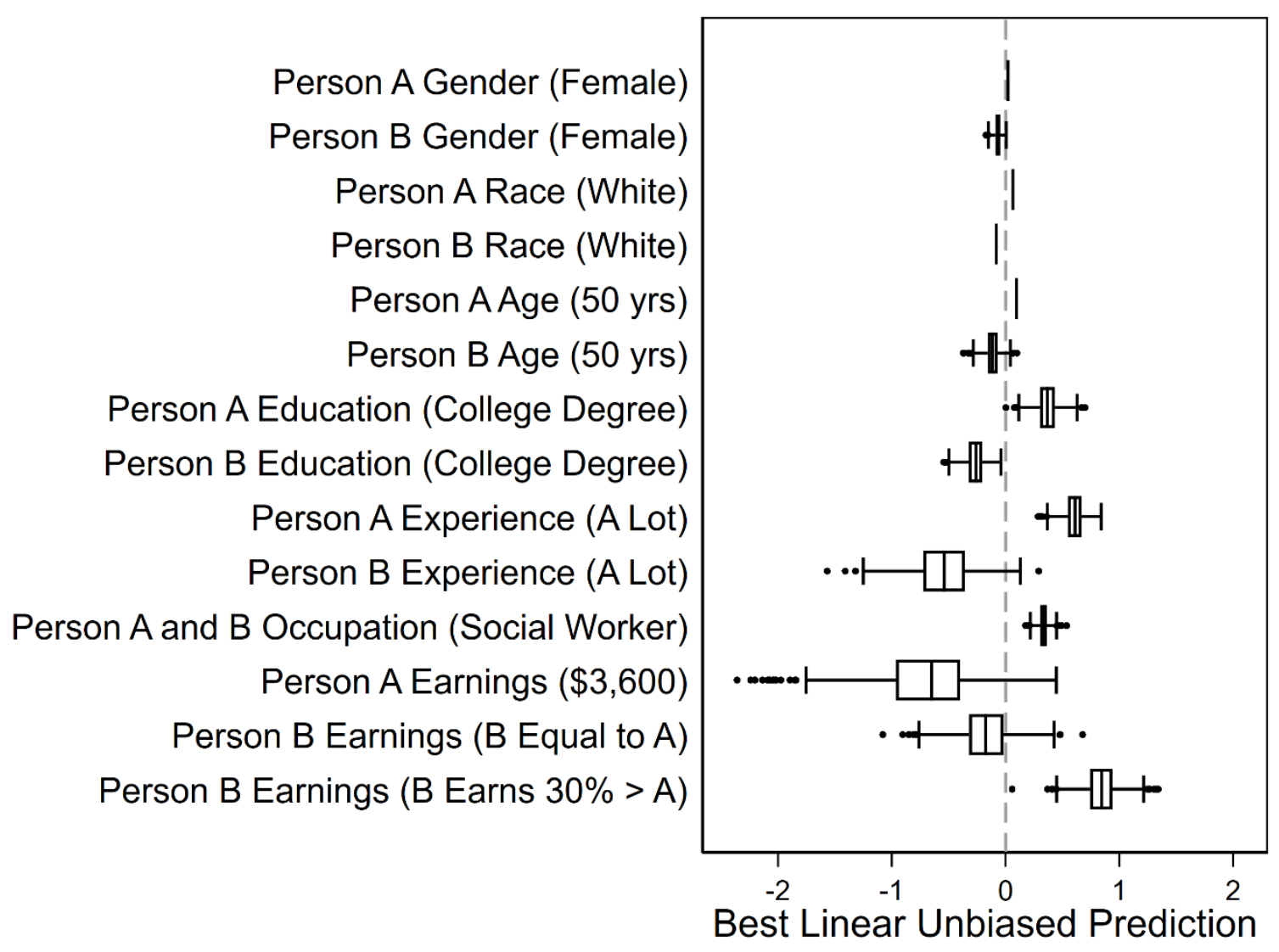

Figure 2. Boxplots of Best Linear Unbiased Predictions of Random Slopes

Note: boxplots show the distributions of magnitudes of each random slope at the individual level. 

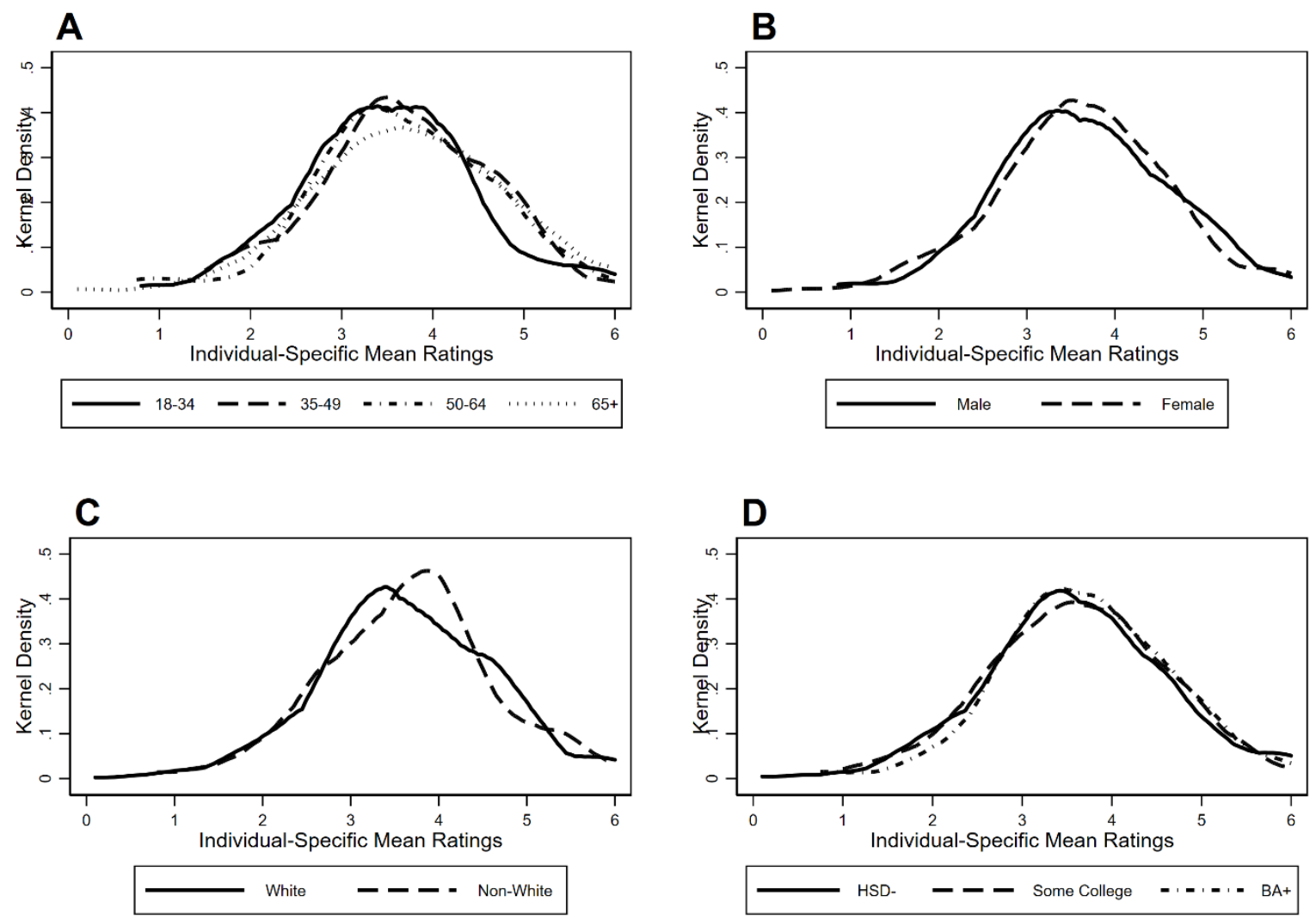

Figure 3. Kernel Density Plots of Individual-Specific Mean Ratings of the Norm of Wage Negotiations by Age (Panel A), Gender (Panel B), Race (Panel C), and Education (Panel D) Note: HSD- = High school diploma or lower, BA+ = Bachelor's degree or higher. 


\section{Supplemental Material}

The Norm of Wage Negotiations in the United States

\section{Contents}

1. Statistical models and estimation

1.1. Ordinary least squares regression and hierarchical linear models .......................................2

2. Modeling assumptions

2.1. First-order serial autocorrelation, heteroskedasticity, etc.

3. Tests of assumptions for unbiased causal identification and inference

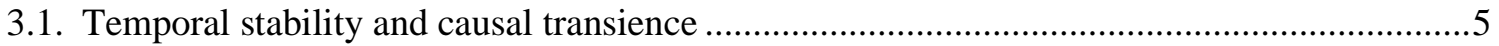

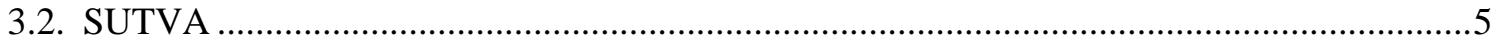

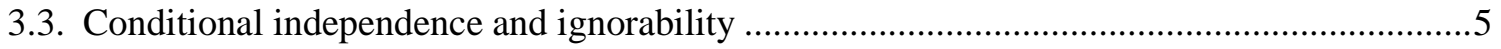

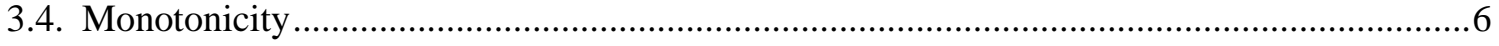

4. References

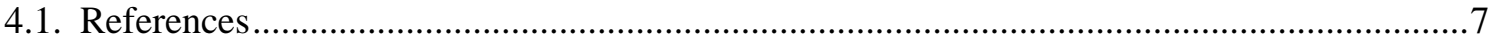

5. Robustness and sensitivity checks

5.1. Figure S1. Ordered Logit Model, Effects of Vignette Dimensions and Fairness ....................34

5.2. Table S1. Ordered Logit Model, Effects of Individual-Level Variables .................................35 


\section{Statistical Models and Estimation}

The research design yields panel data in which $i$ vignettes $(i=1, \ldots, 10)$ are nested within $j$ individuals $(j=1, \ldots, 707)$. As a result, we estimated a series nested ordinary least squares and two-level hierarchical linear models (HLM) with and without higher-level moderation of lowerlevel effects. The various models we estimated in the main text can be found below.

To begin, we assumed that all respondents could be characterized by a single regression equation. In other words, all respondents had the same tendency to prescribe or proscribe wage negotiations and that all respondents placed the same weight on the circumstances governing the norm of wage negotiations (i.e., fixed intercept and fixed slopes model). The single equation we specify was a classic ordinary least squares regression with robust standard errors given by:

$$
Y_{i}=\beta_{0}+\beta_{k} X_{k i}+\delta_{i} V_{i}+\varepsilon_{i},
$$

where $Y$ denotes the norm rating, $X_{k}$ represent the vector of regressors (i.e., vignette dimensions and levels), $V_{i}$ denote the vector of vignette dummy variables for vignettes 2 through 10 (vignette 1 is the referent category), $\beta_{0}$ denotes the intercept, $\beta_{k}$ denote slope coefficients for $X_{k}$, $\delta_{i}$ denote slopes coefficients for $V_{i}, \varepsilon$ denotes the error term (i.i.d.), and $i$ indexes the vignette. Although not shown in the main text, the results suggest a reasonable fit to the data $\left(N=6499, \chi^{2}(23)=\right.$ 1149.20, $p<.001)$.

Next, we relaxed the assumption that respondents had the same tendency to prescribe or proscribe wage negotiations by estimating a two-level random intercept and fixed slopes HLM. This model allowed each respondent to have a unique intercept for the ten evaluated vignettes, but retained the restriction that a single slope for each respective regressor characterized all respondents. The two equations specified were given by:

$$
Y_{i j}=\beta_{0 j}+\beta_{k} X_{k i j}+\delta_{i} V_{i}+r_{i j},
$$

where Equation 2 was a level-1 (or within-level) model that paralleled Equation 1 except for the addition of $j$, which indexes individual respondents, and the use of $r_{i j}$, which denotes a random error term (i.i.d) that varies over the population of vignettes. We also specified a level- 2 model of between-individual variation in ratings by modeling the intercept, $\beta_{0 j}$, from Equation 2:

$$
\beta_{0 j}=\gamma_{00}+\gamma_{0 k} W_{k j}+u_{0 j},
$$

where $\gamma_{00}$ refers to the overall population intercept for ratings of the norm of wage negotiations (which is the grand mean of ratings across all individuals), $W_{k j}$ denotes a vector of individuallevel regressors, $\gamma_{0 k}$ refers to slope coefficients for $W_{k j}$, and $u_{0 j}$ denotes a random error term (i.i.d) for the deviation of the intercept of an individual from the overall population intercept $\gamma_{00}$.

Next, we relaxed the assumption of fixed slopes, so that each respondent had both a unique intercept and a unique slope for each vignette dimension (i.e., a two-level random intercept and 
random slopes HLM). To accomplish this task, we included an additional equation to the model specified in Equations 2 and 3:

$$
\beta_{k j}=\gamma_{k 0}+\gamma_{k k} W_{k j}+u_{k j}
$$

where $\beta_{k j}$ denotes a vector of slope coefficients for $X_{k i j}$ in respondent $j, \gamma_{k 0}$ is a vector of overall population slope coefficients for $X_{k i j}, W_{k j}$ refers to a vector of individual-level regressors, $\gamma_{k k}$ denotes slope coefficients for $W_{k j}$, and $u_{k j}$ is a vector of random error terms (i.i.d) for the deviation of the slopes of individual $j$ from the overall population slopes $\gamma_{k 0}$.

Note that when we probed the character of the norm of wage negotiations in the main text (e.g., polarity and intensity), we constrained $\gamma_{0 k}$ in Equation 3 and $\gamma_{k k}$ in Equation 4 to zero. These two parameters were freed when we investigated whether the norm of wage negotiations and the conditions governing the norm of wage negotiations varied across subpopulations (see Tables 4 and 5 in the main text). 


\section{Modeling Assumptions}

Tests revealed that the estimates presented in the results section were not unduly influenced by outliers (results available upon request). We did, however, find first-order serial autocorrelation of the level-1 disturbance terms (Woolridge test for first-order autocorrelation, $F(1,675)=$ 4.723, $p=.030$ ), and heteroscedastic level-1 errors (Breusch-Pagan test for heteroscedasticity, $\chi^{2}$ $(1)=34.64, p<.001)$. As a result, robust standard errors with a first-order autoregressive structure were used throughout.

To test for possible fatigue effects and other issues related to repeated measures (e.g., unobserved effects that might influence all cases to the same degree for a specified ith vignette), we regressed norm ratings on dummy variables for vignette number with the first vignette serving as the referent category. A Wald test for the joint significance of the vignette dummy variables rejected the null hypothesis that the vignette dummy variables were identical across the 10 vignettes, $\chi^{2}(9)=35.11, p<.001$. As a result, we include a vector of vignette dummy variables in the level-1 model (see Equation 1).

Because we randomly assigned levels of each dimension to vignettes and randomly assigned respondents to design-based experimental treatments, we assume that the vignette dimensions are orthogonal to the level-1 and level-2 errors terms (see Equations 1 through 4). While we cannot explicitly test the former, we can test whether vignette dimensions are orthogonal to the level-2 random error term with a classic Hausman specification test estimating fixed- and randomeffects econometric models for panel data. In doing so, we rejected the null hypothesis of no systematic differences in coefficients, $\left.\chi^{2}(14)=26.10, p=.025\right)$. In spite of this evidence, the correlation between the vignette dimensions and the level-2 error term was negligible ( $r=$ 0.032 ). 


\section{Assumptions for Unbiased Causal Identification and Inference}

Temporal stability and causal transience. First, under two weak assumptions, the assessment of ten vignettes per respondent allows us to estimate unit causal effects in a counterfactual framework and not merely treatment effects on the treated. The two assumptions-temporal stability and causal transience-state that potential outcomes are unaffected by the anticipation of treatments administered in the future (sometimes referred to anticipation effects) and that potential outcomes in one period are unaffected by treatments administered in prior periods (sometimes referred to as spillover effects) (see Holland 1986; Hainmueller et al. 2014; Morgan and Winship 2007).

To test these assumptions, we estimated (a) two-level models in which each vignette dimension interacted with dummy variables for vignette number, and (b) two-level models with vignette dimensions and lagged $\mathrm{t}-1$ vignette dimensions. We found that (a) Wald tests for the joint significance of the interaction terms rejected the null hypothesis that the vignette dimensions were identical across the 10 vignettes, $\chi^{2}(126)=238.49, p<.001$, and (b) $\chi^{2}$ tests for the joint significance of the lagged $\mathrm{t}-1$ vignette dimensions failed to reject the null hypothesis, $\chi^{2}(14)=$ $11.84, p=.619$. With respect to (a), we found that the statistical results were driven by differences in values of Person A's earnings across vignettes. We did not observe a consistent increasing or decreasing effect for Person A's earnings from vignette 1 to 10 . Given the results, we can assume temporal stability and causal transience, and restricting our analysis to the first vignette assessed-even though we lose statistical power-generated substantive findings similar to those presented in the main document.

SUTVA. The stable unit treatment value assumption (SUTVA) states that unit A's potential outcome is solely a function of whether he or she receives the treatment; assignments or treatments applied to units B through $\mathrm{Z}$ have no effect on unit A's potential outcome. A given outcome then is unaffected by treatments assigned to or received by other units. SUTVA, in other words, implies non-interference between units. This assumption is generally maintained in online experiments and shall not be assessed here.

Conditional independence and ignorability. Conditional independence-sometimes referred to as ignorability - is the assumption that values assigned to treatment conditions are independent of potential outcomes (i.e., values taken by dependent variables), where "assigning values" describes the process by which treatments obtain their particular values. By manipulating and randomly assigning vignette dimensions to respondents, we satisfy the assumption of conditional independence as well as three other assumptions that underlie conditional independence: (1) treatment assignment is independent of potential outcomes and values of the dependent variables (i.e., no simultaneity or reflection problems), (2) selection bias is absent, and (3) omitted variable bias is also absent.

To test the assumption of conditional independence we conducted randomization checks. The goal was to look for unexpected correlations between experimental manipulations and observed covariates (e.g., gender). Our randomization checks consisted of regressing each vignette dimension-either logistic or multinomial logistic regression depending on the number of levels per dimension—on the individual-level covariates presented in the main document. We found 
that the observed covariates were jointly non-significant ( $p$-values $>.05$ ) for all of the vignette dimensions, indicating support for the assumption of conditional independence.

Monotonicity. The assumption of monotonicity states that there are no units that receive a treatment if assigned to the control group (Angrist et al. 1996; Gerber and Green 2012); or, more generally, that respondents do not do the opposite of his or her assignment, no matter what the assignment. Angrist et al. (1996) classify four types of subjects: (1) compliers: subjects who take the treatment if assigned to the treatment condition; (2) never-takers: subjects who avoid the treatment if assigned to the treatment condition; (3) always-takers: subjects who take the treatment if assigned to the control condition; and (4) defiers: subjects who do the opposite of their assignment; they avoid the treatment if assigned to it, and they take the treatment if assigned to the control group. Angrist et al. (1996) refer to never-takers, always-takers, and defiers jointly as noncompliers. The presence of noncompliers-and defiers in particular — can downwardly bias average treatment effects. In some experimental designs (e.g., natural experiments like the Vietnam War draft) and in most observational studies, the assumption of monotonicity is frequently violated. But, like classic laboratory experiments, our research design rules out noncompliers by making treatment unavailable to those in the control group and the control unavailable to those in the treatment group. Thus, our assumption of monotonicity is likely valid. 


\section{References}

Angrist, Joshua D., Guido W. Imbens, and Donald B. Rubin. 1996. "Identification of Causal Effects Using Instrumental Variables.” Journal of the American Statistical Association 91: 444-455.

Gerber, Alan S. and Donald P. Green. 2012. Field Experiments: Design, Analysis, and Interpretation. New York, NY: W. W. Norton \& Company.

Hainmueller, Jens, Daniel J. Hopkins, and Teppei Yamamoto. 2014. “Causal Inference in Conjoint Analysis: Understanding Multidimensional Choices via Stated Preference Experiments.” Political Analysis 22: 1-30.

Holland, Paul W. 1986. "Statistics and Causal Inference.” Journal of the American Statistical Association 81: 945-960.

Morgan, Stephen L. and Christopher Winship. 2007. Counterfactuals and Causal Inference: Methods and Principles for Social Research. Cambridge, MA: Cambridge University Press. 


\section{Robustness and Sensitivity Checks}

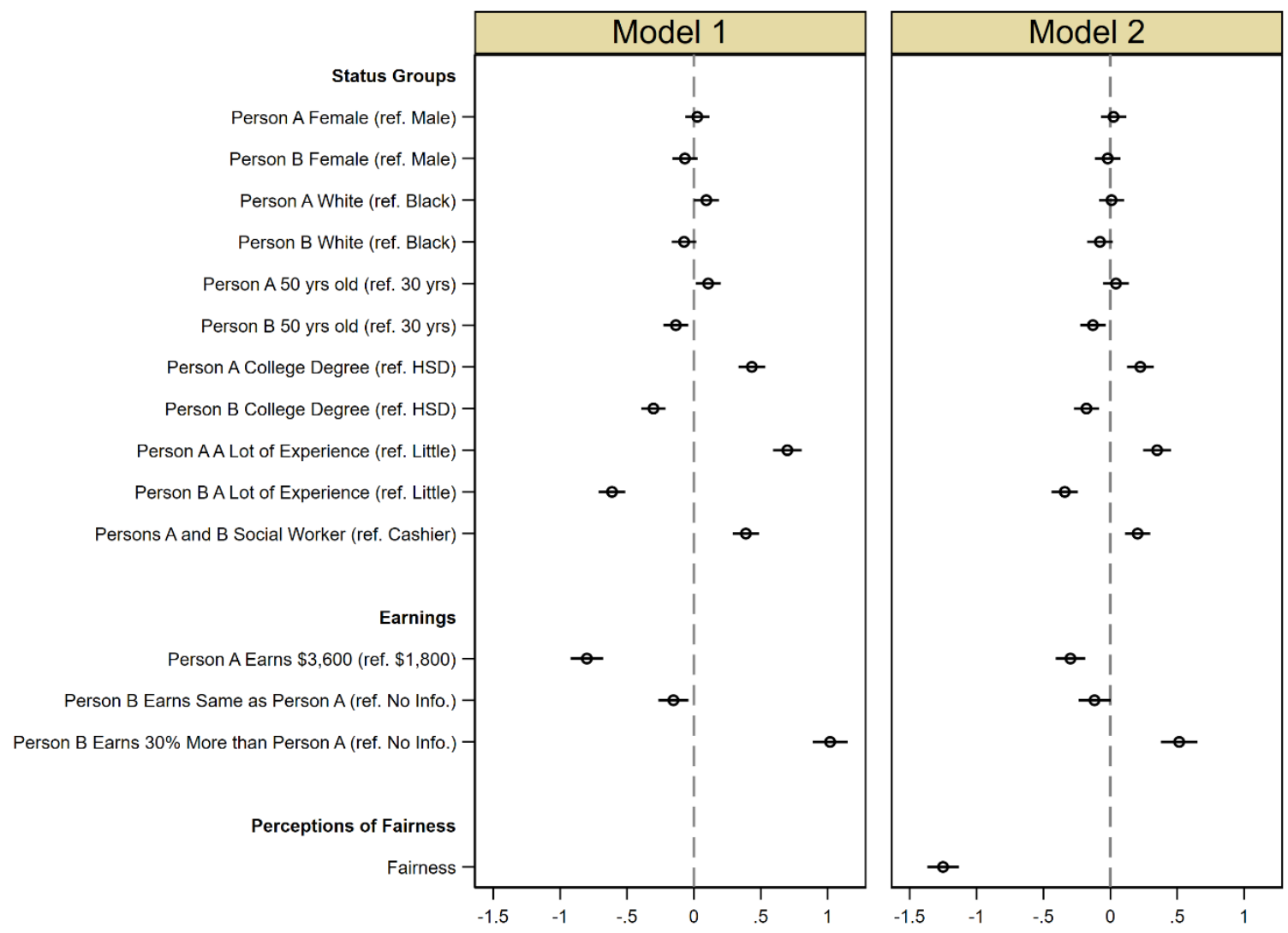

Figure S1. Two-Level Ordered Logit Coefficients of Vignette Dimensions and Fairness of Earnings on the Norm of Wage Negotiations

Notes: Bars around coefficients reflect 95\% CIs. HSD = high school diploma. No Info. $=$ no information about Person B's earnings. 
Table S1. Consensus of the Norm of Wage Negotiations across

Subpopulations, Two-Level Hierarchical Ordered Logit Model

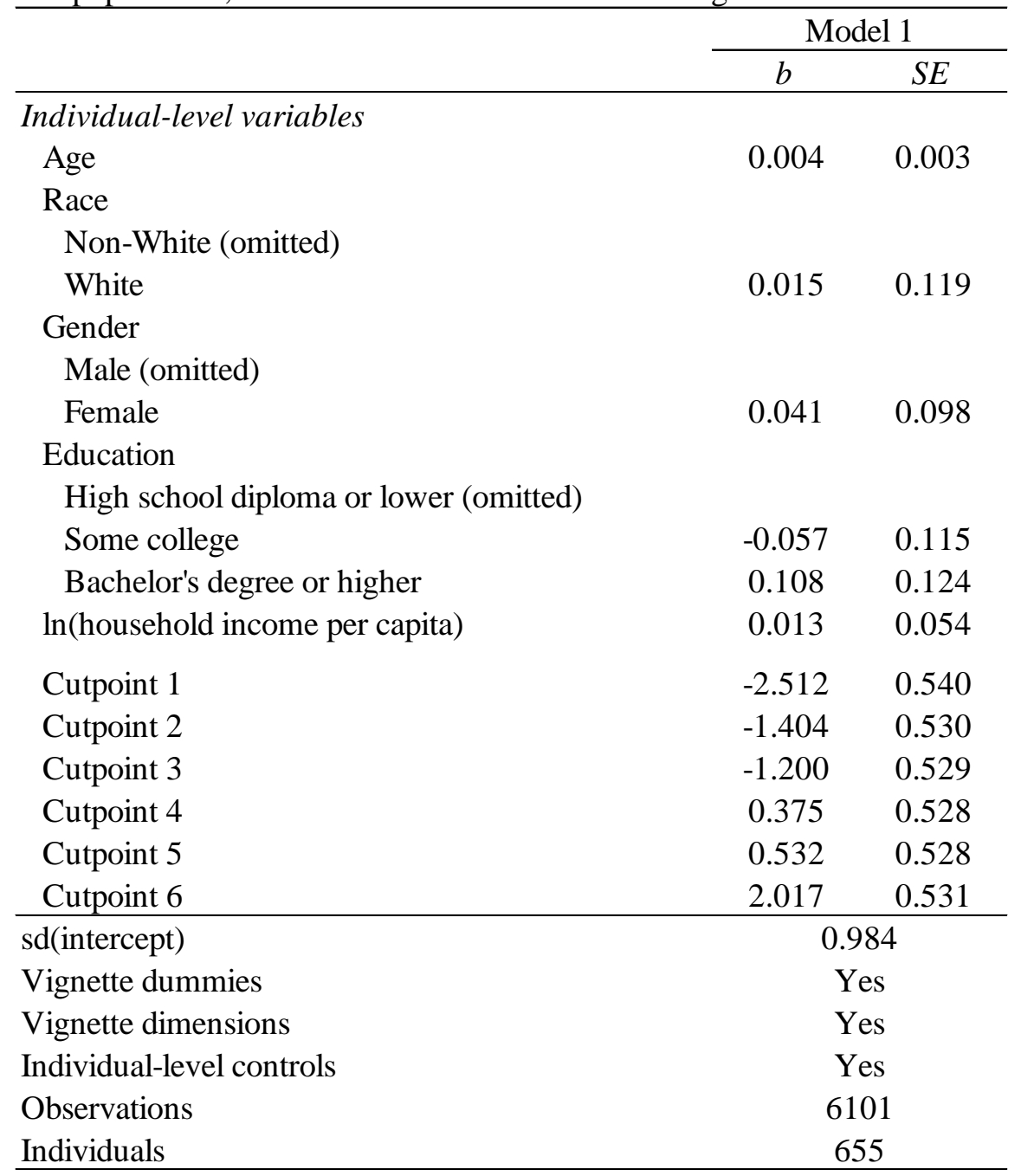

*** $p<0.001, * * p<0.01, * p<0.05$ (two-tailed)

Note $: b=$ unstandardized slopes, $S E$ = robust standard errors. Control

variables included marital status, cohabitation status, employment status, and U.S. region. 